\title{
A probabilistic model for determining the effect of post-weld treatment on the fatigue performance of tubular bridge joints
}

\author{
Scott Walbridge *, Alain Nussbaumer \\ Steel Structures Laboratory - ICOM, Ecole Polytechnique Fédérale de Lausanne - EPFL, CH-1015 Lausanne, Switzerland
}

Received 8 November 2005; received in revised form 14 February 2006; accepted 27 April 2006

Available online 30 June 2006

\begin{abstract}
Herein, a probabilistic model for predicting the effect of post-weld treatment on the fatigue performance of the welded joints in tubular truss bridges is described. Specifically, a probabilistic LEFM-based model is first developed for the fatigue analysis of single untreated and treated crack sites in tubular $K$-joints. A systems reliability approach is then proposed for the analysis of tubular structures with multiple potential crack sites. Using this approach, it is then demonstrated that significant improvements in the fatigue reliability of tubular joints with dimensions common to bridge structures can be obtained with post-weld treatment, even when the influences of the various untreated and treated potential crack sites are considered.
\end{abstract}

(c) 2006 Elsevier Ltd. All rights reserved.

Keywords: Tubular bridge joints; Post-weld treatment; Fracture mechanics; Fatigue; Systems reliability

\section{Introduction}

In the design of tubular truss bridges, that is bridges consisting of steel tubes welded together to form truss girders, engineers have found the fatigue performance of the joints to be a critical aspect [1-3]. This means that larger member sizes and welds must often be specified than would be required to meet static strength requirements alone $-\mathrm{a}$ fact that hinders the ability of these structures to compete economically with more conventional bridge types. In looking for ways of improving this performance, the use of residual stress-based post-weld treatment methods such as needle peening has been suggested.

To study this possibility, large-scale fatigue tests were carried out by Schumacher [1,2], which demonstrated the ability of needle peening to increase the fatigue lives of tubular $K$-joints with dimensions common to bridge structures (i.e. $\gamma=0.5 \cdot D / T<12$, see Fig. 1). Although encour-

\footnotetext{
* Corresponding author. Present address: University of Waterloo, Department of Civil Engineering, 200 University Avenue West, Waterloo, Ont., Canada N2L 3G1. Tel.: +1 519888 4567; fax: +1 5198884349.

E-mail address: swalbrid@civmail.uwaterloo.ca (S. Walbridge).
}

aging, a number of concerns with the use of these methods have limited the extent to which such findings can be translated into practical guidelines. Firstly, although their ability to increase the average fatigue lives of welded structural details is well documented (see, for example: $[4,5])$, there is some concern in general about the reliability of these methods. Secondly, in the fatigue tests cited above, it was seen that the benefit of treating the critical crack location (determined by prior testing and deterministic analysis), although substantial, was eventually limited by cracking at a less critical, untreated site.

As a result of these concerns, it was concluded that in order to determine the extent to which post-weld treatment methods such as needle peening can be used to improve the fatigue performance of tubular bridge structures, a probabilistic analytical model was needed that was capable of considering the influences of the various potential crack sites (untreated and/or treated) on the overall fatigue reliability of the structure. Herein, such a model is developed. This model is founded on a deterministic, linear elastic fracture mechanics (LEFM)-based model developed previously for predicting the fatigue lives of single potential crack sites (untreated and treated) in welded plate stiffener details [6]. 


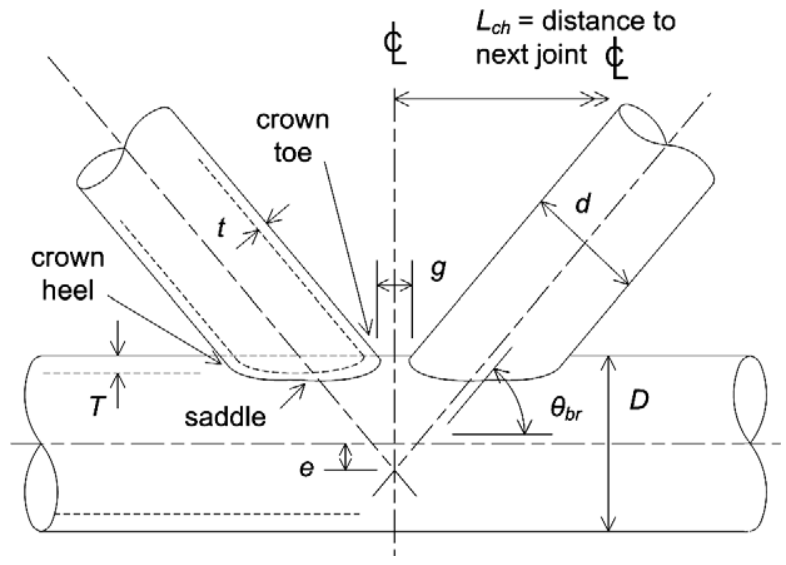

Fig. 1. Non-overlapping single $K$-joint.

Herein, this deterministic model is first modified for the analysis of single potential crack sites in tubular $K$-joints. It is then transformed into a probabilistic model for predicting the reliability of these crack sites. Several studies are carried out using this model. A systems reliability approach for the analysis of tubular structures with multiple potential crack sites is then proposed and demonstrated. As well as providing useful information regarding one potential means of improving the fatigue performance of tubular bridge joints, it is believed that the current work represents a step forward in the study of the treatment methods themselves, which to date has consisted primarily of laboratory testing and deterministic analysis. Although its possible applications are believed to be wide-ranging, the immediate scope of the current work is limited to non-overlapping single $K$-joints (see Fig. 1) such as those common to planar Warren truss bridges and residual stress-based treatment methods such as needle peening.

\section{Fatigue tests on tubular bridge joints}

Fig. 2 shows the specimen configuration used in the fatigue tests reported in $[1,2]$. The specimens (shaded area in Fig. 2) were fabricated from S355 steel. Four series of spec-
Table 1

Tubular joint specimens studied in [1]

\begin{tabular}{|c|c|c|c|c|c|c|c|c|}
\hline \multirow[t]{2}{*}{ Series } & \multirow{2}{*}{$\begin{array}{l}\text { Investigated } \\
\text { parameter }\end{array}$} & \multicolumn{6}{|c|}{ Size $\left(\mathrm{mm},{ }^{\circ}\right)$} & \multirow{2}{*}{$\begin{array}{l}\Delta Q \\
(\mathrm{kN})\end{array}$} \\
\hline & & $D$ & $T$ & $d$ & $t$ & $g$ & $\theta_{\mathrm{br}}$ & \\
\hline & - & 273 & 20 & 139.7 & 12.5 & $20-29$ & 60 & 594 \\
\hline 2 & $\begin{array}{l}\text { No backing } \\
\text { ring }\end{array}$ & 273 & 20 & 139.7 & 12.5 & $54-60$ & 60 & 594 \\
\hline & Smaller joint & 168.3 & 12.5 & 88.9 & 8.0 & $31-44$ & 60 & 396 \\
\hline S4 & Site 1 treated & 273 & 20 & 139.7 & 12.5 & $57-67$ & 60 & 594 \\
\hline
\end{tabular}

imens were tested with two specimens in each series (16 joints in total). The varied parameters are summarized in Table 1. In this table (see also Fig. 1), $D, d, T$, and $t$ are the chord and brace diameters and wall thicknesses, $g$ is the gap at the crown toe of the joint, and $\theta_{\mathrm{br}}$ is the brace angle. All of the specimens were the same size except those in Series S3. All of the specimens had short backing rings to facilitate proper application of the first weld pass, except those in Series S2. In Series S4, the effect of post-weld treatment of the critical crack location (by needle peening [5] see Fig. 3) was examined. In all of the tests, a cyclic load, $\Delta Q\left(=Q_{\max }-Q_{\min }\right)$, was imposed at a frequency of $2 \mathrm{~Hz}$.

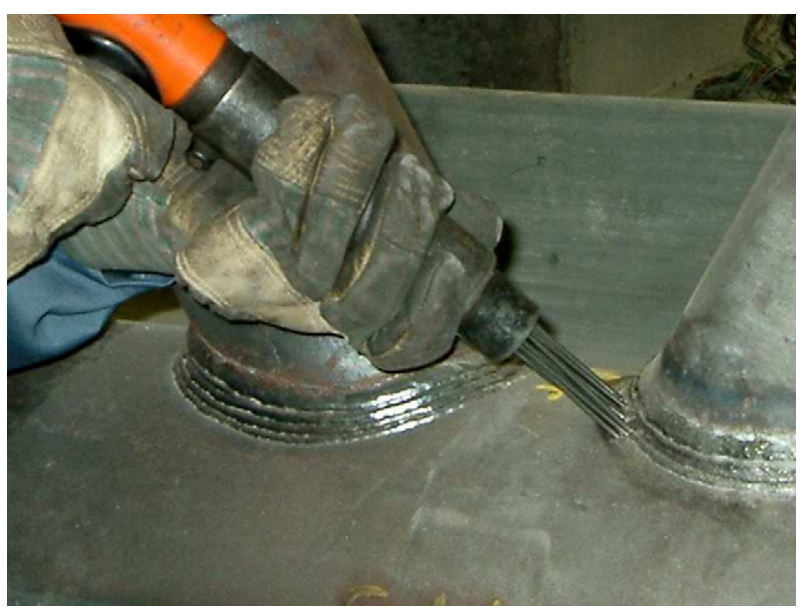

Fig. 3. Needle peening of test specimens [1].

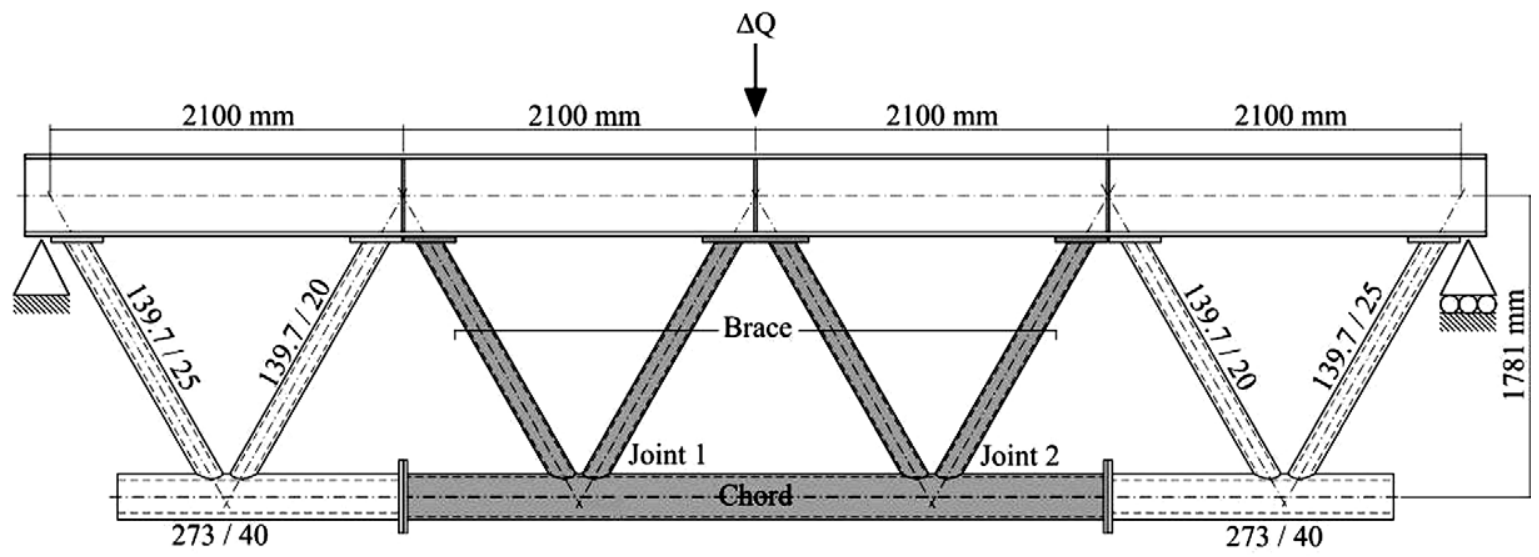

Fig. 2. Tubular truss specimen configuration used in [1]. 


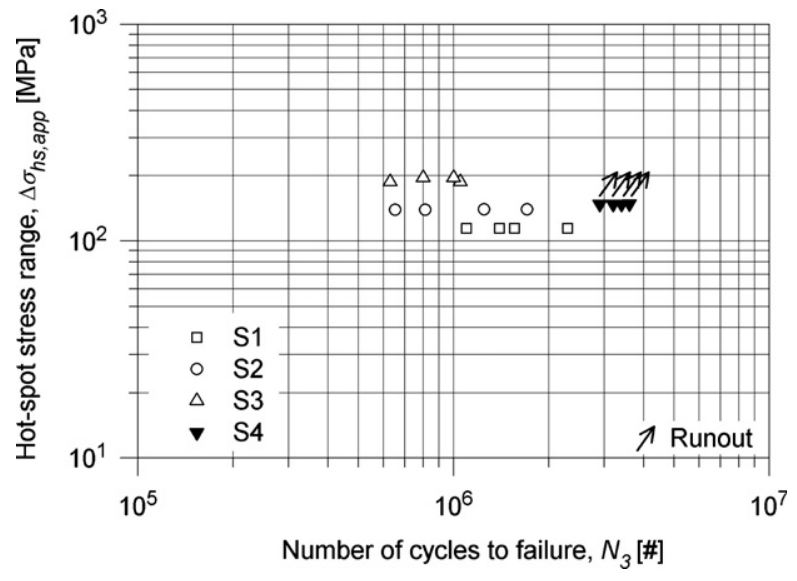

Fig. 4. Results of tests reported in [1].

This load was fixed at $\Delta Q=594 \mathrm{kN}$ for the Series $\mathrm{S} 1 / 2 / 4$ tests, and $\Delta Q=396 \mathrm{kN}$ for the Series $\mathrm{S} 3$ tests. The applied load ratio, $R\left(=Q_{\min } / Q_{\max }\right)$, was fixed at 0.1 .

The results of these fatigue tests are summarized in Fig. 4. In this figure, the number of cycles to failure, $N$, is plotted as a function of the applied hot-spot stress range, $\Delta \sigma_{\mathrm{hs}, \mathrm{app}}$, where hot-spot stress, $\sigma_{\mathrm{hs}}$, is defined as the surface stress at the crack location or hot-spot including all of the stress raising effects of the structural detail, but excluding those due to the local weld profile itself [1-3]. Failure is defined as through-thickness cracking at any location in the joint, or $N_{3}$ failure according to van Wingerde et al. [7]. Runouts or specimens for which $N_{3}$ failure did not occur are indicated with an arrow.

Based on these test results, it was concluded that the use of a backing ring did not significantly affect the fatigue lives of the joints. Looking at Fig. 4 it can be seen that the fatigue lives of the treated joints (Series S4) are significantly greater than those of the untreated joints of similar size (Series $\mathrm{S} 1 / 2$ ). As discussed in [1,2], if characteristic $S-N$ curves corresponding with a $95 \%$ survival probability are compared, then the calculated improvement in the fatigue strength of the joint due to the treatment is more than

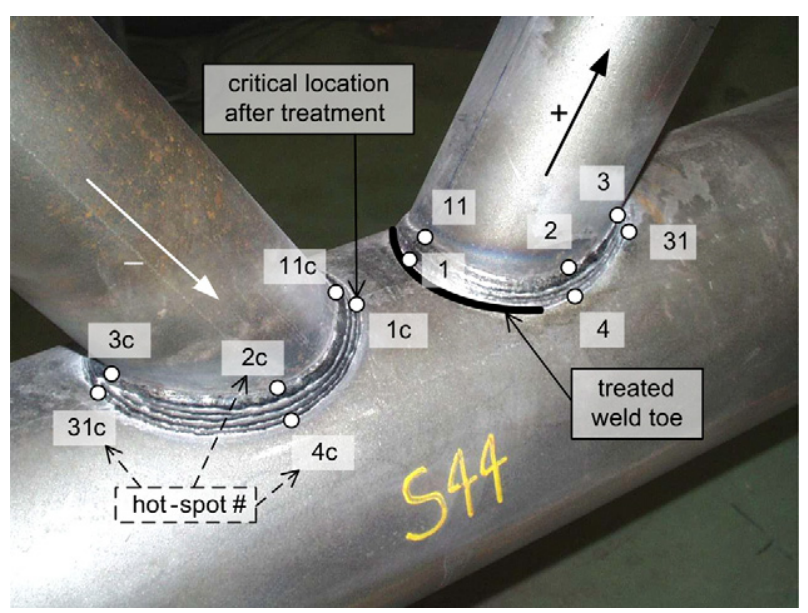

Fig. 5. Shift of crack location with treatment [1].
$50 \%$. If these $S-N$ curves are assumed to have a constant slope of $m=3.0$ on a $\log -\log$ plot of stress versus fatigue life, then this can be shown to correspond with an improvement in fatigue life of over $300 \%$.

During these tests it was observed that treatment of the critical location, that is Site 1 on the tension $(+)$ diagonal (see Fig. 5), while improving the fatigue performance of the joint considerably, resulted in a shift of the eventual crack site away from the treated location to the untreated Site $1 \mathrm{c}$ on the compression (-) diagonal. This was an unexpected result, as discussed in $[1,2]$, but one that could be explained by the presence of tensile residual stresses near the weld toe, which caused crack growth to occur even though the applied cyclic stress was entirely compressive.

\section{Deterministic LEFM model for single crack sites}

Following the large-scale fatigue tests, a deterministic LEFM-based analysis was carried out to determine whether or not the test results could be predicted analytically. A range of deterministic models are available for the fatigue analysis of welded details, with varying levels of accuracy and complexity. For the current study, a model was desired that would provide a sufficient level of accuracy, while at the same time being simple enough that it could be transformed into a probabilistic model, to be used later for the analysis of large numbers of potential crack sites on entire full-scale tubular bridge trusses.

Towards this end, a deterministic model based on the work of Bremen [6] was adopted. This model employs the basic assumption that the critical initial defects in tubular bridge joints can be represented as small, semi-elliptical surface cracks along the toes of the joint welds. A second, fundamental assumption made by the model is that post-weld treatment methods such as needle peening work primarily by introducing compressive residual stresses near the treated surface. These stresses have the effect of reducing crack growth rates in the early part of the stable growth phase of the total fatigue life. Other effects of the treatment, such as the possible beneficial smoothing of the discontinuity at the weld toe, the potentially detrimental introduction of small notch-like dents, the beneficial flattening and aligning of the surface grains, the increase in the toughness of the surface layer etc., are all assumed to have an influence that is either negligible or small but beneficial. The model is founded on the well-known Paris-Erdogan crack growth law, modified to consider crack closure effects and the existence of a threshold stress intensity factor (SIF) range, $\Delta K_{\text {th }}$, and integrated over a crack depth range, $a_{0}$ to $a_{\mathrm{c}}$ :

$N_{\mathrm{c}}=\int_{a_{0}}^{a_{\mathrm{c}}} \frac{\mathrm{d} a}{C \cdot\left(\Delta K_{\mathrm{eff}}^{\mathrm{m}}-\Delta K_{\mathrm{th}}^{\mathrm{m}}\right)}$

wherein:

$$
\begin{aligned}
\Delta K_{\mathrm{eff}}= & \operatorname{MAX}\left(K_{\mathrm{app}, \max }-K_{\mathrm{op}}, 0\right) \\
& -\operatorname{MAX}\left(K_{\mathrm{app}, \min }-K_{\mathrm{op}}, 0\right)
\end{aligned}
$$


wherein, $K_{\text {app,max }}$ and $K_{\text {app,min }}$ are the maximum and minimum SIFs due to the applied load and $K_{\mathrm{op}}$ is the applied SIF level at which the crack tip opens upon loading. $K_{\text {op }}$ is calculated as follows:

$K_{\text {op }}=-\left(K_{\text {res }}+K_{\mathrm{pl}}\right)$

wherein $K_{\text {res }}$ is the SIF due to the residual stress distribution along the anticipated crack path and $K_{\mathrm{pl}}$ is the SIF due to the additional stresses that must be present to cause the crack to be closed at SIFs less than $K_{\mathrm{op}} . K_{\mathrm{pl}}$ is calculated using the following empirical expression from [6]:

$K_{\mathrm{pl}}=-\operatorname{MIN}\left(\frac{0.2}{\left(1-R_{\mathrm{eff}}\right)}, 0.28\right) \cdot\left(K_{\mathrm{app}, \max }+K_{\mathrm{res}}\right)$

wherein $R_{\text {eff }}$ is the effective stress ratio, defined as follows:

$R_{\text {eff }}=\frac{K_{\text {app }, \text { min }}+K_{\text {res }}}{K_{\text {app } \text { max }}+K_{\text {res }}}$

Eq. (4) was selected over a number of alternatives. It was thought to be a good choice for the current study, as the data on which it is based includes measurements obtained at high negative applied stress ratios $(R=-1$ to -4$)$. Using Eqs. (1)-(5) the fatigue lives of untreated and treated crack sites can be predicted, given the applied and residual SIFs ( $K_{\text {app }}$ and $K_{\text {res }}$ ) over the crack depth range, the initial and final crack depths $\left(a_{0}\right.$ and $\left.a_{\mathrm{c}}\right)$, and the crack growth parameters $\left(C, m\right.$, and $\left.\Delta K_{\text {th }}\right)$.

A number of approaches are discussed in [3] for calculating $K_{\text {app }}$ and $K_{\text {res }}$ at a given crack depth. Herein, $K_{\text {res }}$ is calculated using the rather well-known approach proposed by Albrecht and Yamada [8]. Specifically, given the residual stress distribution along the anticipated crack path, $\sigma_{\text {res }}(b), K_{\text {res }}$ at a given crack depth, $a$, is calculated using the following expression:

$K_{\text {res }}=Y_{\mathrm{e}} \cdot Y_{\mathrm{s}} \cdot Y_{\mathrm{w}} \cdot Y_{\mathrm{g}} \cdot \sigma_{\text {res }} \cdot \sqrt{\pi \cdot a}$

wherein $\sigma_{\text {res }}$ is a measure of the residual stress magnitude (such as the surface stress), and:

- $Y_{\mathrm{e}}$ is the so-called shape factor (for an elliptical crack),

$-Y_{\mathrm{S}}$ is the free surface factor,

- $Y_{\mathrm{w}}$ accounts for the finite thickness of the plate or tube wall, and

- $Y_{\mathrm{g}}$ accounts for the non-uniformity of the stress distribution along the crack path.

Herein, the factors $Y_{\mathrm{e}}, Y_{\mathrm{s}}$, and $Y_{\mathrm{w}}$ are calculated using the following expressions:

$$
\begin{aligned}
& Y_{\mathrm{e}}=\frac{1}{\int_{0}^{\pi / 2}\left(\sqrt{1-\sin ^{2} \phi \cdot\left(\left(c^{2}-a^{2}\right) / c^{2}\right)}\right) \cdot \mathrm{d} \phi} \\
& Y_{\mathrm{s}}=1+0.12 \cdot\left(1-0.75 \cdot \frac{a}{c}\right) \\
& Y_{\mathrm{w}}=\sqrt{\left(\frac{2 \cdot T}{\pi \cdot a}\right) \cdot \tan \left(\frac{\pi \cdot a}{2 \cdot T}\right)}
\end{aligned}
$$

wherein $\phi$ is an angle describing the location around the crack perimeter, $a$ is the crack depth, $c$ is half of the semi-elliptical crack width, and $T$ is the thickness of the cracked plate or tube wall. Regarding these expressions, Eq. (7) is an exact solution derived by integral transformation [8,9], and Eqs. (8) and (9) are empirical relationships $[8,10,11] . Y_{\mathrm{g}}$ is calculated according to [8]. Specifically, the stress distribution present in the uncracked structure is modelled as a series of $n$ discrete uniform stress pairs acting over the crack depth. $Y_{\mathrm{g}}$ is then calculated by summing the effects of each stress pair, as follows:

$Y_{\mathrm{g}}=\left(\frac{2}{\pi}\right) \cdot \sum_{i=1}^{n} \frac{\sigma_{b_{i}}}{\sigma_{\text {res }}} \cdot\left\{\sin ^{-1}\left(\frac{b_{i+1}}{a}\right)-\sin ^{-1}\left(\frac{b_{i}}{a}\right)\right\}$

wherein $b_{i}$ is the distance from the plate or tube wall surface to the discrete stress or stress range pair $\sigma_{b i}$.

The adopted residual stress distributions along the anticipated crack path due to the welding and post-weld treatment processes are based on measurements reported by others $[6,12]$. The residual stress distribution due to the welding process is defined by the following expression:

$$
\begin{aligned}
\sigma_{\text {weld }}(b)= & f_{\mathrm{y}} \cdot\left(0.62+2.327 \cdot\left(\frac{b}{T}\right)-24.125 \cdot\left(\frac{b}{T}\right)^{2}\right. \\
& \left.+42.485 \cdot\left(\frac{b}{T}\right)^{3}-21.087 \cdot\left(\frac{b}{T}\right)^{4}\right)
\end{aligned}
$$

wherein $b$ is the depth below the surface, $T$ is the thickness of the cracked tube wall, and $f_{\mathrm{y}}$ is the yield strength. This is essentially the empirical expression proposed in [12], shifted to represent an average of the measured data, rather than an upper bound. For modelling the residual stresses due to post-weld treatment a stress distribution similar to the one proposed in [6] is employed. This distribution is based on X-ray diffraction measurements of residual stresses due to shot, needle, and hammer peening, made on a longitudinally stiffened plate specimen after imposing a number of high amplitude nominal stress cycles to consider the possibility of residual stress relaxation. This distribution takes the following form:

$$
\begin{aligned}
& \sigma_{\mathrm{pwt}}(b)=-f_{\mathrm{y}} \cdot(0.5) \quad \text { if } b \leqslant 0.1 \cdot d_{\mathrm{p}} \\
& \sigma_{\mathrm{pwt}}(b)=f_{\mathrm{y}} \cdot\left(\left(\frac{b}{d_{\mathrm{p}}}\right) \cdot\left(\frac{5}{6}\right)-\left(\frac{7}{12}\right)\right) \text { if } b>0.1 \cdot d_{\mathrm{p}}
\end{aligned}
$$

wherein, $d_{\mathrm{p}}$ is the imprint diameter of the peening tool. To determine the combined stress distribution, $\sigma_{\text {res }}(b)$, the logical parameter $P W T$ is introduced. This parameter is set to equal one if the crack site is treated, or zero if it is not treated. The residual stress distribution is then described as follows:

$$
\begin{aligned}
& \sigma_{\text {res }}(b)=\operatorname{MIN}\left(\sigma_{\text {pwt }}(b), \sigma_{\text {weld }}(b)\right) \quad \text { if } P W T=1 \\
& \sigma_{\text {res }}(b)=\sigma_{\text {weld }}(b) \quad \text { if } P W T=0
\end{aligned}
$$




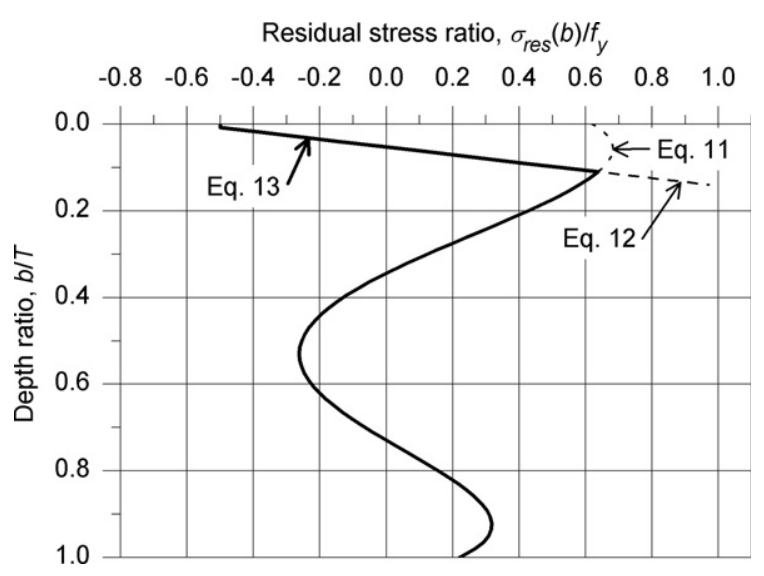

Fig. 6. Residual stress distribution for a needle peened crack site $(T=20 \mathrm{~mm})$.

An example of the modelled stress distribution for a needle-peened crack site is presented in Fig. 6.

If the applied stress distribution is known, $K_{\text {app }}$ can be calculated in the same manner as $K_{\text {res }}$. Normally, in order to obtain this stress distribution, a finite element (FE) analysis must be carried out. For the analysis of the large numbers of potential crack sites in entire tubular bridge trusses, however, it was quickly realized that this would be a prohibitively time-consuming step. Fortunately, design aids have been developed by others that allow this step to be circumvented, although presumably with some influence on the accuracy of the model. To calculate $K_{\text {app }}$ herein, the approach proposed by Bowness and Lee [13] is employed. Specifically, $K_{\text {app }}$ is calculated directly, using the following expression:

$$
\begin{aligned}
K_{\mathrm{app}}= & \left(M k_{\mathrm{m}} \cdot Y_{\mathrm{m}} \cdot(1-D O B)+M k_{\mathrm{b}} \cdot Y_{\mathrm{b}} \cdot D O B\right) \\
& \cdot \sigma_{\mathrm{hs}, \mathrm{app}} \cdot \sqrt{\pi \cdot a}
\end{aligned}
$$

wherein $M k_{\mathrm{m}}$ and $M k_{\mathrm{b}}$ are magnification factors for the membrane and bending stress cases, $Y_{\mathrm{m}}$ and $Y_{\mathrm{b}}$ are correction factors for these same stress cases, and $\sigma_{\mathrm{hs} \text {,app }}$ is the applied hot-spot stress at the location of interest. The degree of bending, $D O B$, is defined as follows:

$$
D O B=\frac{\sigma_{\mathrm{b}}}{\sigma_{\mathrm{b}}+\sigma_{\mathrm{m}}}
$$

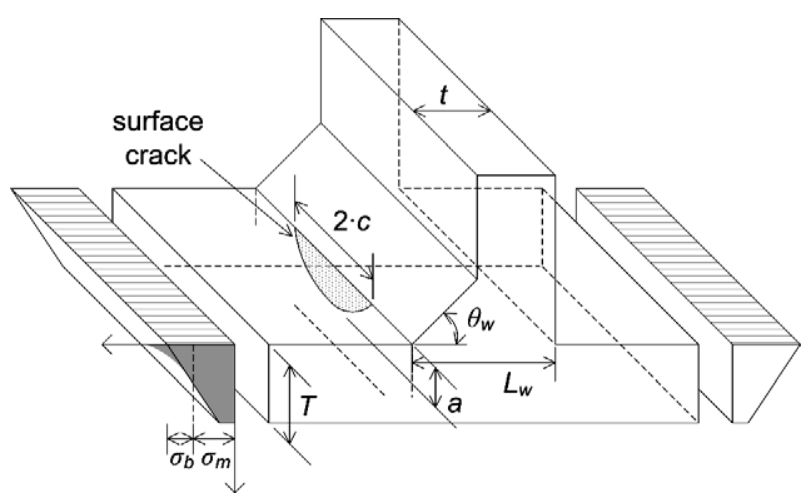

Fig. 7. Crack at the weld toe of a $T$-butt joint. wherein $\sigma_{\mathrm{m}}$ and $\sigma_{\mathrm{b}}$ are the membrane and bending stresses through the thickness of the tube wall.

The basis for employing this approach in the current context is the assumption that weld toe cracks in tubular joints essentially behave like similar cracks in a $T$-butt joints such as the one in Fig. 7.

Given the applied hot-spot stress, $\sigma_{\mathrm{hs}, \mathrm{app}}$, the degree of bending, $D O B$, the crack shape parameters: $a$ and $c$, the wall thickness of the cracked member, $T$ (or $t$ ), and the weld geometry parameters: $L_{\mathrm{w}}$ and $\theta_{\mathrm{w}}$ (see Fig. 7), Eq. (14) can be solved, using:

- the Bowness and Lee parametric equations for the magnification factors, $M k_{\mathrm{m}}$ and $M k_{\mathrm{b}}$. The basis for these equations was an FE analysis-based parametric study of $T$-butt joints with different geometries and crack shapes [13]. They require as input the following parameters: $a / T, a / c, L_{\mathrm{w}} / T$, and $\theta_{\mathrm{w}}$.

- the Newman and Raju [14] parametric equations for the correction factors, $Y_{\mathrm{m}}$ and $Y_{\mathrm{b}}$. The basis for these equations was an FE analysis-based study of surface cracks in flat plates under pure membrane and bending stress conditions. They require as input the following parameters: $a / T$ and $a / c$.

The applied hot-spot stress, $\sigma_{\mathrm{hs}, \text { app }}$, and degree of bending, $D O B$, can determined in a number of ways. Specifically, the former can be determined by surface strain measurements such as those reported in [1], obtained during the tests discussed in the previous section. Alternatively, it can be determined by FE analysis (using a relatively coarse mesh) or by multiplying the more easily obtained nominal member stresses, $\sigma_{\text {nom }}$, for various simple load cases, by stress concentration factors or $S C F$ s and summing the resulting terms, as discussed in [1-3]. The degree of bending, $D O B$, can also be determined by $\mathrm{FE}$ analysis or using parametric equations such as the ones proposed by Connolly et al. [15], which are based on an FE analysis-based study using two-dimensional thin shell elements. In using these equations for bridge applications, however, it may be necessary to make assumptions for load cases that are not covered, and it may also be necessary to ignore the lower limit on $\gamma$ of 7.6 [3].

A final piece of information that is needed to perform fatigue calculations using the model described above concerns the manner in which the crack shape evolves as the crack increases in depth. Herein, a one-dimensional crack propagation model is employed and the aspect ratio, $a / c$, varied according to a predefined crack shape evolution function. According to this function, the initial aspect ratio $(a / c)_{0}$ may vary, but this ratio then evolves smoothly, converging on a fixed value of 0.2 at $b / T=0.25$ [3].

In comparing the fatigue lives predicted by the model with the test results reported in [1,2], one objective was to confirm that the model was able to predict the observed shift of the eventual crack site, due to the localized 
treatment of Site 1 (see Fig. 5). Towards this end, three cases were investigated:

- Case 1-NT: Site 1 not treated (critical for Series S1/2),

- Case 1-T: Site 1 treated, and

- Case 1c-NT: Site 1c not treated (critical for Series S4).

Table 2 summarizes the input parameter values used in the comparison between the predicted fatigue lives and the test results for these three cases. Regarding this table, the following comments are made:

- The applied hot-spot stress range, $\Delta \sigma_{\mathrm{hs}, \mathrm{app}}$, at Site 1 (Cases 1-NT and 1-T) and the $D O B$ were determined by an FE analysis carried out by Schumacher [1]. At Site 1c (Case 1c-NT), the hot-spot stress range was assumed to be compressive, with a magnitude of $60 \%$ of the stress at Site 1, based on strain gauge and speckle interferometry measurements also reported in [1].

- The critical crack depth, $a_{\mathrm{c}}$, was taken as half of the wall thickness, $T$, for the Site 1 cracks, and $7.6 \mathrm{~mm}$ for the crack at the untreated Site 1c. The former limit was selected rather than the normal $N_{3}$ failure crack depth of $a=T$, due to concerns regarding the validity at greater crack depths of the simplified method proposed in [8] for calculating $Y_{\mathrm{g}}$. The latter limit is based on the measured crack depth for a treated specimen that was sectioned after testing as discussed in [3].

- The imprint diameter of the peening tool, $d_{\mathrm{p}}$, was taken as $1.5 \mathrm{~mm}$ for needle peening.

- In calculating the welding and post-weld treatment residual stresses, $f_{\mathrm{y}}=355 \mathrm{MPa}$ was assumed. This corresponds with the characteristic yield strength for S355 steel. Another choice might have been the mean value for this parameter; however the lower, characteristic value was used in the current study on the basis that this would result in conservative estimates of the treatment benefit.

Table 2

Deterministic input parameters

\begin{tabular}{lllcl}
\hline Parameter & \multicolumn{2}{l}{ Case } & \multicolumn{2}{l}{ Units } \\
\cline { 2 - 4 } & $1-\mathrm{NT}$ & $1-\mathrm{T}$ & $1 \mathrm{c}-\mathrm{NT}$ & \\
\hline$T$ & 20 & 20 & 20 & $\mathrm{~mm}$ \\
$\theta_{\mathrm{w}}$ & 43 & 43 & 43 & $\circ$ \\
$L_{\mathrm{w}}$ & 20.6 & 20.6 & 20.6 & $\mathrm{~mm}$ \\
$a_{0}$ & 0.2 & 0.2 & 0.2 & $\mathrm{~mm}$ \\
$(a / c)_{0}$ & 0.8 & 0.8 & 0.8 & - \\
$\Delta \sigma_{\mathrm{hs}, \mathrm{app}}$ & 143 & 143 & -86 & $\mathrm{MPa}$ \\
$D O B$ & 0.84 & 0.84 & 0.84 & - \\
$R$ & 0.1 & 0.1 & 0.1 & - \\
$P W T$ & $0(\mathrm{no})$ & $1($ yes $)$ & $0(\mathrm{no})$ & - \\
$d_{\mathrm{p}}$ & - & 1.5 & - & $\mathrm{mm}$ \\
$C$ & $2.0 \times 10^{-13}$ & $2.0 \cdot 10^{-13}$ & $2.0 \times 10^{-13}$ & $(\mathrm{~mm} / \mathrm{cycle})$ \\
& & & & $\left(\mathrm{N} / \mathrm{mm}^{-3 / 2}\right)^{m}$ \\
$m$ & 3.0 & 3.0 & 3.0 & - \\
$\Delta K_{\mathrm{th}}$ & 0.0 & 0.0 & 0.0 & $\mathrm{MPa} \sqrt{\mathrm{mm}}$ \\
$a_{\mathrm{c}}$ & $0.5 \cdot T$ & $0.5 \cdot T$ & 7.6 & $\mathrm{~mm}$ \\
\hline
\end{tabular}

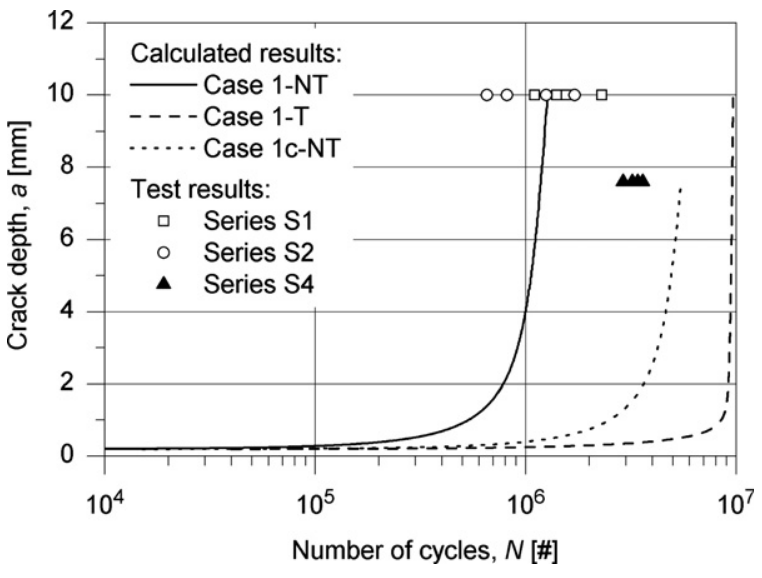

Fig. 8. Comparison of deterministic model and test results.

Eq. (1) was solved by numerical integration using a subroutine written in the programming language FORTRAN 90 for each of the cases described in Table 2. The results are presented in Fig. 8. In this figure, it can be seen that the model predicts well the test results for the untreated specimens, which all failed at the untreated Site 1 (Case 1-NT). On the other hand, the model over-predicts the test results for the Series S4 specimens, all of which cracked at the untreated Site 1c. This over-prediction ranges from $51 \%$ to $88 \%$. This may have been due to poor choices for one or more of the input parameters. In order to study this possibility, a probabilistic calibration was carried out, as discussed in the next section.

With the crack propagation curves in Fig. 8, the two failure modes observed in the Series $\mathrm{S} 1 / 2 / 4$ fatigue tests can be explained. To do this, the untreated specimens comprising Series $\mathrm{S} 1 / 2$ can each be considered as structures with two potential crack sites modelled by Cases $1-\mathrm{NT}$ and 1c-NT. Studying the crack propagation curves for these cases, it can be concluded that the failure of such structures should occur at the untreated Site 1 (Case 1 -NT) first (after $1.23 \times 10^{6}$ cycles). At the time of failure, the theoretical crack at the untreated Site 1c has a depth of approximately $0.35 \mathrm{~mm}$, which is not much larger than the assumed initial crack depth of $0.2 \mathrm{~mm}$ (see Table 2). The treated specimens comprising Series S4, can each be similarly considered as structures with two potential crack sites modelled by Cases 1-T and 1c-NT. Studying the crack propagation curves for these cases, it can be concluded that for such structures, failure should occur at the untreated Site $1 \mathrm{c}-\mathrm{NT}$ (after $5.14 \times 10^{6}$ cycles). This represents an improvement in fatigue life over that of the untreated joint of $\sim 320 \%$ - very close to the value cited in $[1,2]$.

\section{Probabilistic model for single crack sites}

In order to transform the deterministic model described in the previous section into a probabilistic model, the following three steps were followed: 
- First, a suitable definition of failure or limit state function was established.

- Next, the various sources of uncertainty associated with the deterministic model were considered by representing the input parameters (or additional parameters to be added) as statistical variables.

- Finally, a solution method was adopted to determine the probability of failure, $p_{\mathrm{f}}$, as a function of the number of applied stress cycles, $N$, given the information provided in the preceding steps.

The limit state function adopted herein indirectly employed the approach of limiting crack growth to a critical depth, $a_{\mathrm{c}}$. Specifically, the number of cycles required to grow the crack to this depth was denoted $N_{\mathrm{c}}$, and the limit state function, $G(\mathbf{z})$, was defined as follows:

$G(\mathbf{z})=N_{\mathrm{c}}-N=\int_{a_{0}}^{a_{\mathrm{c}}} \frac{\mathrm{d} a}{C \cdot\left(\Delta K_{\mathrm{eff}}^{m}-\Delta K_{\mathrm{th}}^{m}\right)}-N$

A certain error should be expected when using a limit state function based an arbitrarily defined critical crack depth, $a_{\mathrm{c}}$ (such as $a_{\mathrm{c}}=0.5 \cdot T$ or $T$ ). For non-redundant welded structural details, which spend most of their fatigue lives at the smaller crack depths, this error should be small. For highly redundant structures such as tubular joints, however, a certain reserve is known to exist beyond the time required to cause through-thickness cracking. According to [7], for example, the time to total joint failure $\left(N_{4}\right.$ failure) is on average $49 \%$ greater than the time to through-thickness cracking ( $N_{3}$ failure). Ignoring this reserve capacity should therefore result in conservative probability of failure estimates for redundant structures such as tubular joints. When comparing similar joints, this approach may also facilitate meaningful estimates of the relative fatigue performance, as in this case the effects of redundancy will presumably be similar for the two joints. On the other hand, caution should be exercised when ignoring this reserve capacity in the comparison of joint configurations that are very different, as in such cases this approach may erroneously favour one joint configuration over the other. When analyzing entire tubular trusses, a similar logic can be applied. In other words, the proposed approach is presumably suitable for comparing similar truss configurations, but not ones with largely differing levels of redundancy.

The representation of the various input parameters as statistical variables in the probabilistic fatigue analysis of welded structures is discussed in numerous references, i.e.: [16-20]. Detailed discussion regarding the statistical variables used in the current study can be found in [3].

One area where practically no guidance appears in the existing literature, concerns the probabilistic modelling of the residual stresses due to the welding and post-weld treatment processes. A brief discussion of this aspect of the model is thus presented herein. The guidance in the existing literature on the probabilistic modelling of the residual stresses due to welding can be summarized as follows:
- Shetty and Baker [16-18] model the maximum tensile residual stress due to welding (at the surface of a cracked tube wall) using a lognormal distribution with a mean of $300 \mathrm{MPa}$ and a standard deviation of $75 \mathrm{MPa}$ $(\mathrm{COV}=0.25)$ for steel with a characteristic yield strength of $355 \mathrm{MPa}$. Residual stress measurements on tubular joints by Porter Goff et al. [21] are cited as the basis for this distribution. In [17], the residual stress distribution due to welding is modelled as a linear bending stress, tensile on the exterior surface (and to a depth below the surface of $b / T=1 / 3$ ) and compressive on the interior surface of the tube wall. The justification given for this choice is that solutions are readily available to facilitate the rapid calculation of the SIFs for this stress distribution. This distribution is subsequently multiplied by a factor that decreases from one to zero as the crack propagates through the tube wall to account for dissipation of the residual stresses with crack growth.

- Lukic [20] assumes a uniform residual stress due to welding through the wall thickness of stiffened plates. This stress is assumed to follow a lognormal distribution with a mean of $420 \mathrm{MPa}$ and a standard deviation of $42 \mathrm{MPa}(\mathrm{COV}=0.1)$ for $\mathrm{S} 355$ steel plates, $16-40 \mathrm{~mm}$ in thickness.

- The JCSS Code [22] recommends that the residual stress due to welding be assigned a lognormal distribution with a mean value of $300 \mathrm{MPa}$ and a standard deviation of $60 \mathrm{MPa}(\mathrm{COV}=0.2)$.

In order to consider uncertainties in the welding residual stresses, Eq. (11) was modified as follows:

$$
\begin{aligned}
\sigma_{\text {weld }}(b)= & f_{\mathrm{y}} \cdot\left(0.62+2.327 \cdot\left(\frac{b}{T}\right)-24.125 \cdot\left(\frac{b}{T}\right)^{2}\right. \\
& \left.+42.485 \cdot\left(\frac{b}{T}\right)^{3}-21.087 \cdot\left(\frac{b}{T}\right)^{4}\right) \cdot V A R_{\text {weld }}
\end{aligned}
$$

In this expression, the statistical variable $V A R_{\text {weld }}$ was assumed to follow a normal distribution with a mean of 1.0 and a standard deviation of 0.25 . In other words, the COV proposed in [16-18] was adopted, but the estimated mean surface stress of $0.62 \cdot f_{\mathrm{y}}$ was retained. In fact, the use of a mean surface stress of $0.62 \cdot f_{\mathrm{y}}$ with Eq. (17) gives similar results to those obtained using the linear stress distribution and higher surface stress proposed in [16-18] (assuming $f_{\mathrm{y}}=355 \mathrm{MPa}$ ) except near the surface $(b / T<0.1)$.

No consideration was given to the possibility of residual stress dissipation with crack growth, as it is believed that although the residual stresses at the crack face will dissipate due to the presence of the crack, the stress distribution in close proximity to the crack face will remain unchanged, affecting further crack growth in a manner similar to that of the same stress distribution acting on the crack face.

In Fig. 9, the residual stress distribution calculated using Eq. (17) is plotted, along with the data from six measure- 


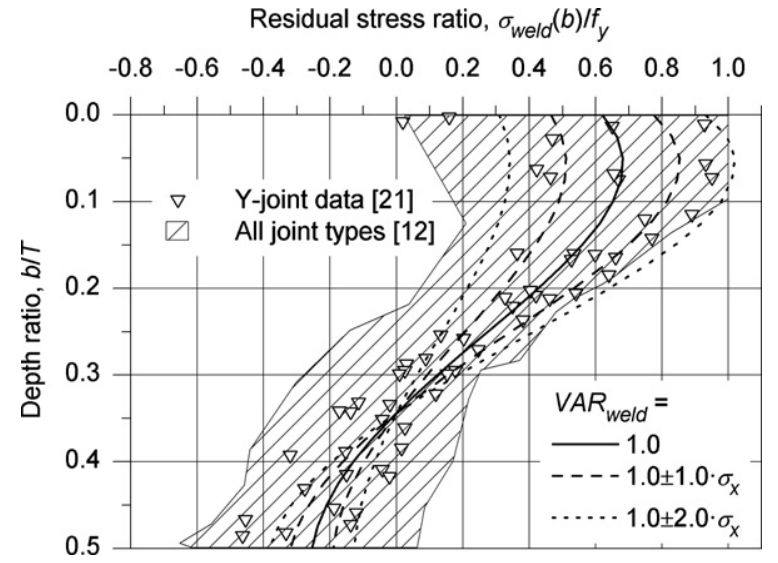

Fig. 9. Eq. (17) compared with measured residual stresses due to welding.

ments on two welded Y-joints reported in [21] and an envelope of the residual stress data for various tubular joint types reported in [12]. In this figure, the stress distribution for $V A R_{\text {weld }}=1.0$ is plotted along with the \pm 1.0 and 2.0 standard deviation $\left(\sigma_{x}\right)$ envelopes. Comparing these envelopes with the measured data it can be seen that near the surface, the highest tensile residual stresses due to welding reported in $[12,21]$ are basically enclosed by the $V A R_{\text {weld }}=$ $1.0 \pm 2.0 \cdot \sigma_{x}$ envelope. In some cases, however, the lowest residual stresses at the surface fall below this envelope. At greater depths $(b / T \approx 1 / 3)$, pinching of the residual stress distributions is predicted by Eq. (17), which does not appear to be reflected in the data for various joint types reported in [12]. A much better match with the measured behaviour can be seen, however, when only one joint type is considered, such as the Y-joint data from [21].

No guidance was found in the literature regarding the consideration of uncertainties in the residual stress distribution due to post-weld treatment. Although these stress distributions have been measured by a number of researchers, the number of measurements reported is often too small to serve as a basis for meaningful statistical analysis. Thus, lacking a viable alternative, an estimate of the uncertainty associated with the treatment stress distribution was made herein using the data presented in [6].

As a first step, Eq. (12) was modified to incorporate the statistical variable $V A R_{\mathrm{pwt}}$ as follows:

$$
\begin{aligned}
\sigma_{\mathrm{pwt}}(b) & =-f_{\mathrm{y}} \cdot\left(V A R_{\mathrm{pwt}}\right) \quad \text { if } b \leqslant 0.1 \cdot d_{\mathrm{p}} \\
\sigma_{\mathrm{pwt}}(b) & =f_{\mathrm{y}} \cdot\left(\left(\frac{b}{d_{\mathrm{p}}}\right) \cdot\left(\frac{5}{6}\right)-\left(\frac{1}{12}+V A R_{\mathrm{pwt}}\right)\right) \\
\text { if } b & >0.1 \cdot d_{\mathrm{p}}
\end{aligned}
$$

The $V A R_{\text {pwt }}$ variable was then assumed to follow a normal distribution with a mean of 0.50 and a standard deviation of 0.10 . In other words, the surface stress of $-0.5 \cdot f_{\mathrm{y}}$ used in the deterministic calculations was retained as the mean. In Fig. 10, the stress distribution calculated using Eq. (18) is plotted with the measured data from [6] for needle peening $\left(d_{\mathrm{p}}=1.5 \mathrm{~mm}\right)$. Again, the distribution for $V A R_{\mathrm{pwt}}=$
1.0 is plotted along with the $\pm 1.0 \cdot \sigma_{x}$ and $2.0 \cdot \sigma_{x}$ envelopes. For the measured data, the timing of the measurement, i.e. before loading, after 1000 applied stress cycles at $\Delta \sigma_{\text {nom }}=200 \mathrm{MPa}(R=0.1)$, and after 1000 additional cycles at $\Delta \sigma_{\mathrm{nom}}=256 \mathrm{MPa}(R=0.1)$, is also indicated.

Comparing the calculated envelopes with the measured data in Fig. 10, it can be seen that, with the exception of a few surface measurements made after the application of the stress cycles, all of the data falls on or above the lower bound of the $V A R_{\text {pwt }}=1.0 \pm 1.0 \cdot \sigma_{x}$ envelope. The measurements made prior to the application of the stress cycles almost all fall above the upper bound of the $V A R_{\mathrm{pwt}}=$ $1.0 \pm 2.0 \cdot \sigma_{x}$ envelope. The choice of the standard deviation for this variable was first made based on such a visual comparison. In order to provide a more solid theoretical basis for the chosen distribution, a maximum likelihood approach was then used to calibrate the estimated mean and standard deviation [3]. This resulted in a mean of 0.56 and a standard deviation of 0.11 . Based on this calibration, it was decided that the visually determined parameters characterized reasonably well the uncertainty associated with the post-weld treatment stresses, and could therefore be retained.

The distributions adopted for the other statistical variables employed by the probabilistic model are summarized in Table 3. The following comments are made regarding these variables:

- For the analysis of test specimens under constant amplitude loading conditions, $\sigma_{\mathrm{hs}, \min }$ and $\sigma_{\mathrm{hs}, \max }$ were determined as a function of the applied stress range, $\Delta \sigma$, and ratio, $R$. These parameters were first multiplied by the statistical variables $V A R_{\Delta \sigma}$ and $V A R_{R}$ respectively, to consider the uncertainties associated with the estimation of the nominal member stresses.

- The degree of bending, $D O B$, was multiplied by the statistical variable $V A R_{D O B}$ to consider the uncertainties associated with the estimation of this parameter.

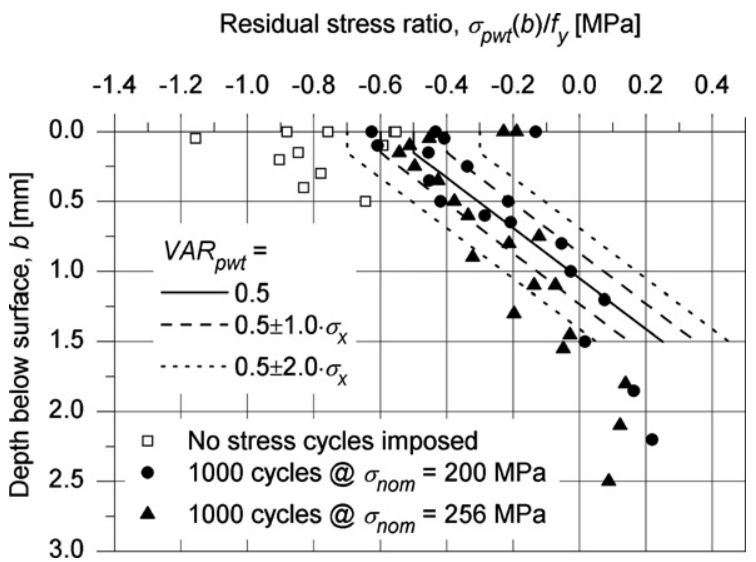

Fig. 10. Eq. (18) compared with measured residual stresses due to needle peening. 
Table 3

Statistical variables

\begin{tabular}{lrllll}
\hline Variable & $i$ & \multicolumn{1}{l}{$\mu_{\mathrm{x}}{ }^{\mathrm{a}}$} & $\sigma_{x}$ & Dist. type & Units \\
\hline$a_{0}$ & 1 & 0.2 & 0.045 & $\mathrm{LN}$ & $\mathrm{mm}$ \\
$(a / c)_{0}$ & 2 & $0.5(0.5)$ & 0.16 & $\mathrm{LN}$ & - \\
$V A R_{\Delta \sigma}$ & 3 & 1.0 & 0.01 & $\mathrm{~N}$ & - \\
$V A R_{R}$ & 4 & 1.0 & 0.01 & $\mathrm{~N}$ & - \\
$V A R_{D O B}$ & 5 & 1.0 & 0.08 & $\mathrm{~N}$ & - \\
$V A R_{S C F}$ & 6 & 1.0 & 0.04 & $\mathrm{LN}$ & - \\
$V A R_{M k}$ & 7 & 1.0 & 0.05 & $\mathrm{LN}$ & - \\
$V A R_{\mathrm{Lw}}$ & 8 & 1.0 & 0.1 & $\mathrm{~N}$ & - \\
$V A R_{\theta \mathrm{w}}$ & 9 & 1.0 & 0.1 & $\mathrm{~N}$ & - \\
$V A R_{\mathrm{weld}}$ & 10 & 1.0 & 0.25 & $\mathrm{~N}$ & - \\
$V A R_{\mathrm{pwt}}$ & 11 & 0.5 & 0.1 & $\mathrm{~N}$ & - \\
$\mathrm{LN}(C)$ & 12 & $-29.24(-28.80)$ & 0.55 & $\mathrm{~N}$ & $\mathrm{LN}((\mathrm{mm} / \mathrm{cycle})$ \\
& & & & & $\left.\left(\mathrm{N} / \mathrm{mm}^{-3 / 2}\right)^{m}\right)$ \\
$\Delta K_{\mathrm{th}}$ & 13 & $100.0(100.0)$ & 15.0 & $\mathrm{LN}$ & $\mathrm{MPa} \sqrt{\mathrm{mm}}$
\end{tabular}

${ }^{\mathrm{a}}$ Note: numbers in ( ) are post-calibration values.

- The weld footprint length and angle, $L_{\mathrm{w}}$ and $\theta_{\mathrm{w}}$, which are needed for the calculation of the magnification factors, $M k$, were multiplied by the statistical variables $V A R_{L \mathrm{w}}$ and $V A R_{\theta \mathrm{w}}$ to consider the uncertainties associated with these parameters.

- The calculated hot-spot stress, $\sigma_{\mathrm{hs}}$, was multiplied by the statistical variables $V A R_{S C F}$ and $V A R_{M k}$ to consider the uncertainties associated with the estimation of the $S C F$, $Y$, and $M k$ parameters.

- In the calculation of the residual stress distribution, $\sigma_{\text {res }}(b)$, the yield stress, $f_{\mathrm{y}}$, was again considered as a deterministic input parameter $\left(f_{\mathrm{y}}=355 \mathrm{MPa}\right)$. This was done based on the assumption that most of the uncertainty in the residual stresses caused by variations in the yield stress was covered by the choices for the parameters describing the $V A R_{\text {weld }}$ and $V A R_{\text {pwt }}$ statistical variables.

As discussed in [3], subroutines employing the first order reliability method (FORM) and Monte Carlo simulation (MCS) solution method were written, again using the programming language FORTRAN 90. In the case of the latter method, a simple importance sampling scheme was employed, which concentrated sampling in a $\mathrm{LN}(C)$ range where early failures were found to be most likely. A total of $1.0 \times 10^{5}$ trials were used for each simulation. The adopted sampling scheme offered a modest increase in the maximum reliability index, $\beta\left(=-\Phi^{-1}\left(p_{\mathrm{f}}\right)\right)$, attainable over crude MCS with the same number of trials.

Using the FORM subroutine, a sensitivity study of the 13 statistical variables was first carried out. Based on this study, the $\mathrm{LN}(C)$ variable was identified as the one to which the results were by far the most sensitive. In addition, the $(a / c)_{0}$ and $\Delta K_{\text {th }}$ variables were seen to have a large effect on the results for the untreated Site 1c (Case 1c-NT), while having a relatively minor effect on the results for the untreated Site 1 (Case 1-NT). This attribute was of particular interest as it was for Case 1c-NT that the deterministic model was seen to give the least accurate results. On this basis, the mean values for the variables $\mathrm{LN}(C),(a / c)_{0}$, and $\Delta K_{\text {th }}$ were calibrated using a maximum likelihood approach. This resulted in a change in the mean of the $\mathrm{LN}(C)$ variable as shown in Table 3 . The means for the other two variables did not change. It should be stated however, that coarse increments were employed in the calibration, and the result may have been influenced by the starting point, which was based on engineering judgement [3].

It should be noted that the use of the calibrated mean for the $\mathrm{LN}(C)$ variable results in a lower estimate of the treatment benefit than if the prior mean is used. In [3], a short review is presented of the values for this parameter recommended by others. From this review, it can be concluded that if the commonly used values for this parameter are employed (i.e. $\mu(\mathrm{LN}(C))=-28.84$ to -29.30 with $m=3.0$ ), rather than the calibrated value of -28.80 , then the calculated treatment benefit will actually be greater.

In order to determine whether or not the probabilistic model could be used to predict the shift in the critical crack site observed in the tests, analyses were first carried out for the three cases examined deterministically in the previous section. The following critical crack depths were assumed:

- For Case 1-NT, a critical crack depth of $a_{\mathrm{c}}=T$ was assumed. This corresponds with the crack depth at the reported number of cycles to $N_{3}$ failure for the Series $\mathrm{S} 1 / 2$ specimens.

- For Case 1-T, a critical crack depth of $a_{\mathrm{c}}=2.0 \mathrm{~mm}$ was assumed. This is intended to correspond with the possibility of a crack at the treated Site 1 (in the Series S4 tests) growing to a size that would likely be detected using the non-destructive testing (NDT) methods employed during these tests.

- For Case 1c-NT, critical crack depths of $a_{\mathrm{c}}=2.0 \mathrm{~mm}$ and $7.6 \mathrm{~mm}$ were assumed.

A limit on the critical crack depth of $a_{\mathrm{c}}=0.5 \cdot T$ was imposed in the previous section due to concerns regarding the validity of the approach proposed in [8] for determining $Y_{\mathrm{g}}$ (in the calculation of $K_{\mathrm{res}}$ ) at larger crack depths. This concern was mitigated for Case 1-NT, however, by the fact that the effective SIF range, $\Delta K_{\text {eff }}$, was known to be equal to the applied SIF range, $\Delta K_{\mathrm{app}}$, for this particular case (i.e. the applied and residual stresses were such that the entire applied stress cycle was effective) and therefore, the effect of this error was known to be negligible [3]. The choice of a detectable crack depth of $2.0 \mathrm{~mm}$ is based on the reported detection in [1] of cracks as small as $3-5 \mathrm{~mm}$ in length.

The results of this study are presented in Fig. 11. Looking at this figure, it can be seen that for the untreated Series $\mathrm{S} 1 / 2$ specimens, the probability of failure, $p_{\mathrm{f}}$, at Site 1 (Case $1-\mathrm{NT}, a_{\mathrm{c}}=T$ ) for a given number of load cycles is always much higher (keeping in mind that a lower $\beta$ means a higher $p_{\mathrm{f}}$ ) than the probability of a detectable crack occurring at Site $1 \mathrm{c}$ (Case $\left.1 \mathrm{c}-\mathrm{NT}, a_{\mathrm{c}}=2.0 \mathrm{~mm}\right)$. When Site 1 is treated, on the other hand, it can be seen that early in 


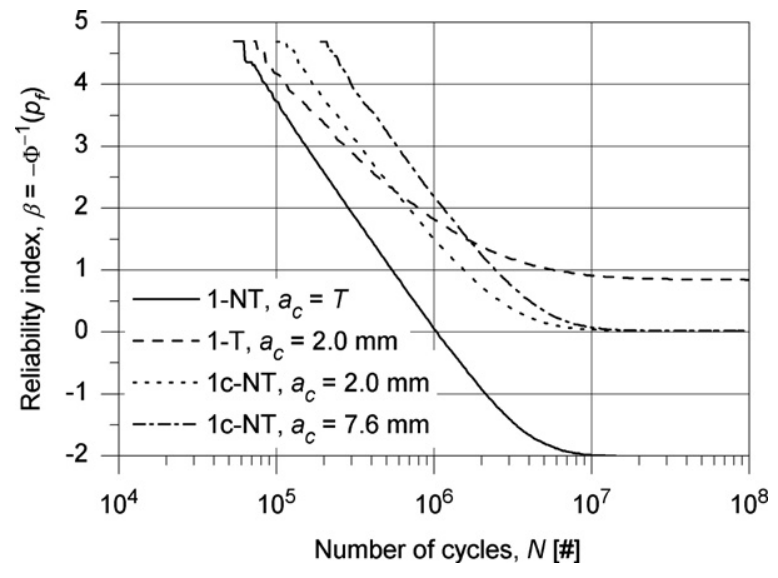

Fig. 11. Probabilistic assessment of critical crack sites in tests.

the fatigue life, the probability of a detectable crack occurring at the treated Site 1 (Case 1-T, $a_{\mathrm{c}}=2.0 \mathrm{~mm}$ ) is in fact higher than the probability of failure of the untreated Site $1 \mathrm{c}$ (Case $1 \mathrm{c}-\mathrm{NT}, a_{\mathrm{c}}=7.6 \mathrm{~mm}$ ). The two curves cross, however, around $\beta \approx 1.5$. Looking at it another way, at the point in time corresponding with the average number of load cycles, $N$, at failure for the Series S4 specimens $\left(3.28 \times 10^{6}\right.$ cycles $)$, the probability of failure at the untreated Site $1 \mathrm{c}$ (Case $1 \mathrm{c}-\mathrm{NT}, a_{\mathrm{c}}=7.6 \mathrm{~mm}$ ) is $\sim 0.26$, versus a probability of having a detectable crack of $\sim 0.14$ for the treated Site 1 (Case 1-T, $a_{\mathrm{c}}=2.0 \mathrm{~mm}$ ). This compares favourably with the observed test results. The closeness of these results suggests, however, that if more specimens had been tested, it is likely that a small crack would have eventually been detected at the treated Site 1 for at least one of the tested specimens.

\section{Studies carried out with probabilistic single site model}

As the statistical variable used to characterize the uncertainty associated with the post-weld treatment residual stress distribution was established based on a relatively small number of measurements, there was some interest in examining the sensitivity of the calculated treatment benefit to variations in the parameters describing this variable. Towards this end, the mean, $\mu()$, and standard deviation, $\sigma()$, of the $V A R_{\mathrm{pwt}}$ variable were varied in order to study the significance of the treatment intensity and quality, assuming these parameters to be suitable measures of these attributes. In this study, the untreated and treated Site 1 cases were compared. The critical crack depth was set to $a_{\mathrm{c}}=0.5 \cdot T$ for all cases.

The studied variations in $\mu\left(V A R_{\mathrm{pwt}}\right)$ and $\sigma\left(V A R_{\mathrm{pwt}}\right)$ can be summarized as follows:

- The treatment intensity, described by the parameter $\mu\left(V A R_{\mathrm{pwt}}\right)$, was set to the following values: $0.75,0.50$, and 0.25 . The intermediate value was assumed to be the normal value for this parameter. The first and last values were assumed to correspond with high and low levels of treatment intensity.
- The treatment uniformity or quality, described by the parameter $\sigma\left(V A R_{\mathrm{pwt}}\right)$, was set to the following values: $0.05,0.10$, and 0.15 . Again, these values were assumed to correspond with high, normal, and low levels of treatment quality.

The results of the treatment intensity study are presented in Fig. 12. In this figure, it can be seen that an increase in the treatment intensity results in a significant increase in the treatment benefit. This benefit can be quantified in a number of ways. For example, in [23], $S-N$ curves for various fatigue details are established corresponding with a $95 \%$ survival probability, based on the statistical analysis of test results for various details and applied stress range levels. This probability can be equated to $p_{\mathrm{f}}=0.05$ or $\beta=1.64$. On this basis, if the fatigue lives corresponding with $\beta=1.64$ are compared for each case in Fig. 12, then the fatigue life improvements for the various treatment intensities can be seen to vary between $67 \%$ and infinity, with an improvement of $510 \%$ calculated for normal intensity treatment.

One concern, raised in Section 1, with post-weld treatment methods is that although they have been shown in test-based studies to increase fatigue life, based (for example) on comparisons of the mean $(50 \%)$ or $95 \%$ survival probability $S-N$ curves of untreated and treated details, such increases have not been confirmed at the higher reliability indices often used in the design of civil engineering structures. In order to address this concern, a higher target index of 3.74 was used in [3] for quantifying the benefit of post-weld treatment. This value corresponds with the target index for a planned service life of 70 years (as specified in [24] for steel bridges in Switzerland), calculated using the most severe annual target index for fatigue suggested in [25] (modified for the planned service life, using the formula provided in the same reference). On this basis, the fatigue life improvements for the various treatment intensities were seen to vary between $44 \%$ and $1030 \%$, with an improvement of $184 \%$ calculated for normal intensity treatment. These improvements can surely be characterized as significant, although it must be acknowledged that they are only representative of what can be expected under highly deterministic, constant amplitude loading conditions. It should also be reiterated that the target index from [3] is employed herein primarily to facilitate quantitative comparisons of untreated and treated potential crack sites at very low probabilities of failure.

The results of the treatment quality study are presented in Fig. 13. In this figure, it can be seen that an increase in treatment quality, corresponding with a decrease in the $\sigma\left(V A R_{\mathrm{pwt}}\right)$ parameter, tends to result in an increase in the benefit of treatment. Comparing Figs. 12 and 13, however, it can be seen that a $50 \%$ increase in the treatment quality tends to result in less of a fatigue life improvement than a similar increase in the treatment intensity. If a target index of $\beta_{\text {target }}=3.74$ is again assumed, then the fatigue life improvements for the various treatment qualities range 


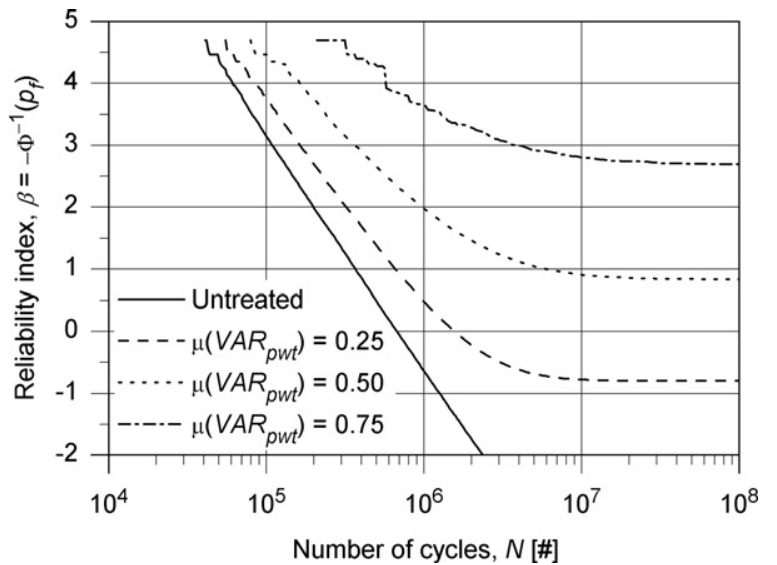

Fig. 12. Effect of treatment intensity on fatigue reliability of a single crack site.

from $111 \%$ to $346 \%$. If $\beta_{\text {target }}=1.64\left(p_{\mathrm{f}}=0.05\right)$ is again assumed, the corresponding improvements range from $295 \%$ to $1060 \%$.

In order to study the influence of the applied stress range, $\Delta \sigma_{\mathrm{hs}, \mathrm{app}}$, and ratio, $R$, on the benefit of post-weld treatment, a study was carried out next where in these parameters were each varied. In this study, the untreated and treated Site 1 were again compared. The treatment parameters for normal intensity/quality needle peening were assumed, i.e.: $d_{\mathrm{p}}=1.5 \mathrm{~mm}, \mu\left(V A R_{\mathrm{pwt}}\right)=0.5$, and $\sigma\left(V A R_{\mathrm{pwt}}\right)=0.1$. The studied variations in $\Delta \sigma_{\mathrm{hs}, \mathrm{app}}$, and $R$ were as follows:

- Four applied hot-spot stress ranges, $\Delta \sigma_{\mathrm{hs} \text {,app }}$, were studied, corresponding with $25 \%, 50 \%, 75 \%$, and $100 \%$ of the assumed mean yield stress, $\mu\left(f_{\mathrm{y}}\right)=385 \mathrm{MPa}$ (note: $f_{\mathrm{y}}=355 \mathrm{MPa}$ was still used in the calculation of the residual stress distributions due to welding and postweld treatment).

- Three applied stress ratios were studied: $R=-0.5,0.1$, and 0.5 .

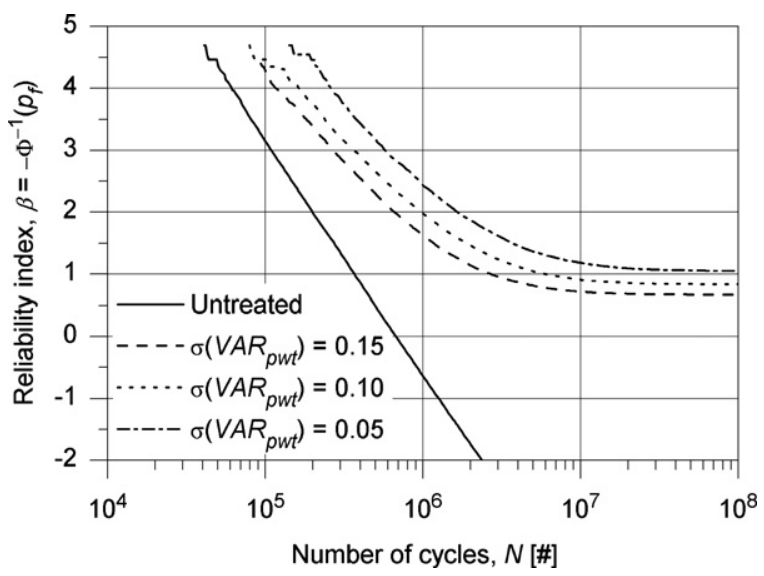

Fig. 13. Effect of treatment quality on fatigue reliability of a single crack site.
The results of this study are presented in Fig. 14. In this figure, the following trends can be observed:

- As expected, it can be seen in all of the graphs in this figure that as the applied stress range, $\Delta \sigma_{\mathrm{hs}, \text { app }}$, increases, the fatigue lives, $N$, corresponding with a given reliability index, $\beta$, decrease. This trend can be seen for both the untreated and treated crack sites.

- The improvement in fatigue performance due to postweld treatment is seen to decrease as the applied stress range, $\Delta \sigma_{\mathrm{hs}, \text { app }}$, increases, for a given stress ratio, $R$.

- As the stress ratio, $R$, is varied, there appears to be little movement in the reliability versus fatigue life curves (on the left) for the untreated crack sites. The reliability curves for the treated crack sites, however, appear to be significantly affected by this parameter. In general, the higher the stress ratio, the lower the improvement in fatigue performance due to post-weld treatment.

- The reliability curves for otherwise identical treated and untreated crack sites never cross according to the proposed model. In other words, the reliability of the treated site is never less than that of the corresponding untreated site for a given fatigue life, $N$.

Fig. 15 presents a summary of the calculated fatigue life improvements due to normal intensity/quality needle peening based on the data in Fig. 14. Again, the improvements in this figure are determined for $\beta_{\text {target }}=3.74$ and 1.64 $\left(p_{\mathrm{f}}=0.05\right)$. In general it can be seen that greater improvements are obtained at lower applied stress ranges and ratios. It can also be seen that the calculated improvement is generally greater if the comparison is made at the lower of the two target indices.

With the calculated fatigue lives for the untreated and treated Site 1 at the different stress range levels, it is possible to construct $S-N$ curves for various target reliability indices, $\beta_{\text {target }}$, and stress ratios, $R$. This is demonstrated in Fig. 16 for $\beta_{\text {target }}=3.74$ and $1.64\left(p_{\mathrm{f}}=0.05\right)$. For the untreated case, these curves were seen to be virtually independent of the stress ratio. Thus, only the $R=0.1$ curves are plotted in this figure. For the treated case, $S-N$ curves are plotted for each of the examined stress ratios. Using curves such as these, the treatment benefit can be determined for various loading conditions.

In Fig. 17, the $S-N$ curves for the untreated Site 1, derived using the results of the study described above, are compared with design $S-N$ curves, based on the results of the large-scale fatigue tests reported in [1]. The first of these design curves is the Detail Category $86\left(\Delta \sigma_{\mathrm{hs}}=86 \mathrm{MPa}\right)$ curve, proposed in [1] for $N_{4}$ (total joint) failure. Using these same test results, it can be shown that the corresponding design curve for $N_{3}$ (through-thickness cracking) failure is Detail Category 75. In both cases, the design curve has been established for a $95 \%$ survival probability $\left(p_{\mathrm{f}}=0.05\right.$, $\beta_{\text {target }}=1.64$ ).

Looking at Fig. 17, it can be seen that the slopes of the calculated $S-N$ curves are similar to those of the design 

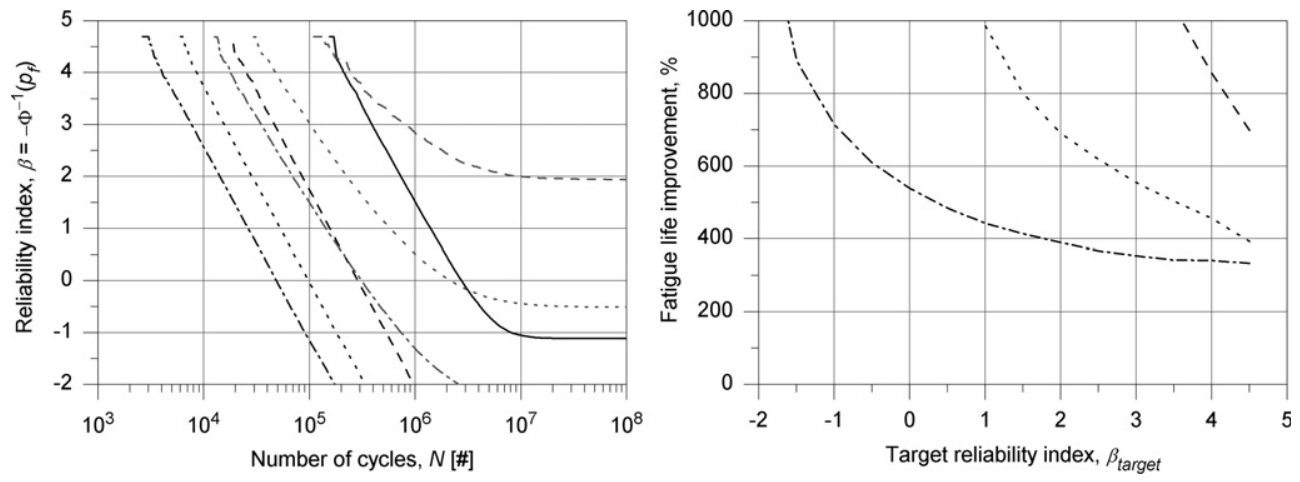

Fig. 14a. Effect of $\Delta \sigma_{\mathrm{hs}, \mathrm{app}}$ on $\beta(R=-0.5)$.
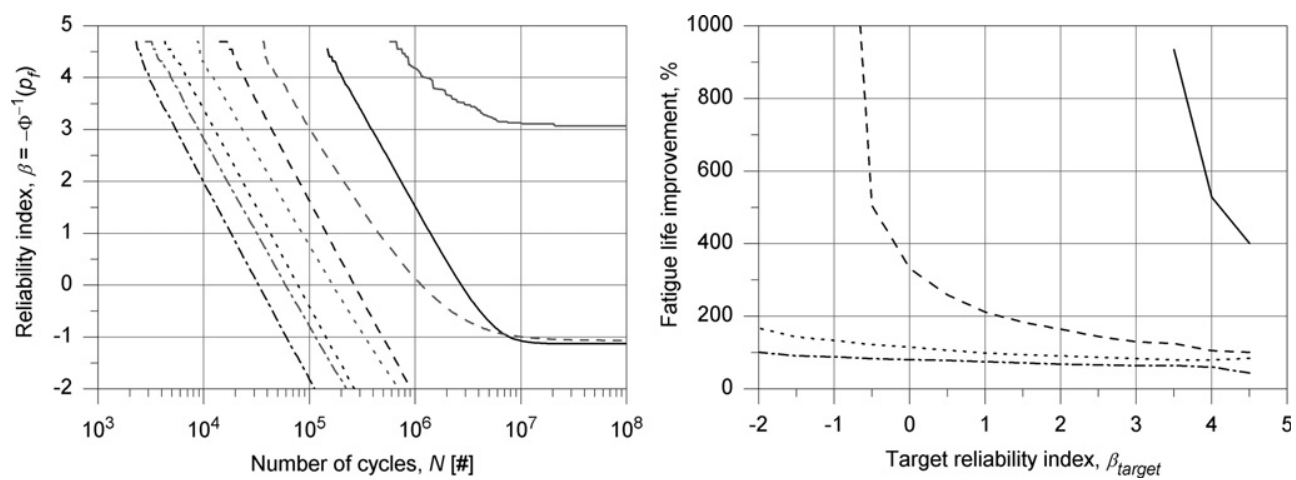

Fig. 14b. Effect of $\Delta \sigma_{\mathrm{hs}, \mathrm{app}}$ on $\beta(R=0.1)$
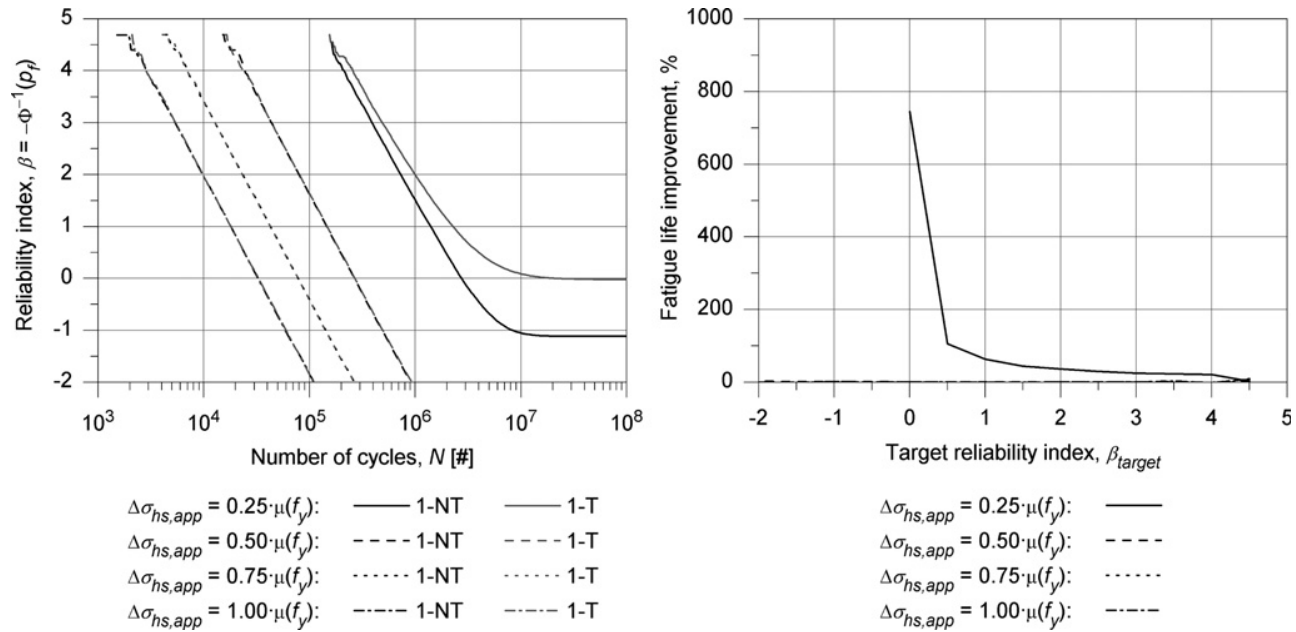

Fig. 14c. Effect of $\Delta \sigma_{\mathrm{hs}, \text { app }}$ on $\beta(R=0.5)$.

curves $(m=3.0)$. The calculated $S-N$ curve corresponding with $\beta_{\text {target }}=3.74$ is much lower than the other curves. The calculated $S-N$ curve for $\beta_{\text {target }}=1.64\left(p_{\mathrm{f}}=0.05\right)$, on the other hand, is very close to the Detail Category 75 design curve. One explanation for the small difference is that the calculated curve corresponds with a slightly more severe failure criterion, that is: $a_{\mathrm{c}}=0.5 \cdot T$.

A final comparison between the test results and the calculated and test-derived $S-N$ curves is presented in Fig. 18.
In this figure, calculated $S-N$ curves corresponding with $\beta_{\text {target }}=1.64$ and zero are compared with design $S-N$ curves corresponding with $95 \%$ and $50 \%$ survival probabilities based on the $N_{3}$ failure criterion, determined using the Series $\mathrm{S} 1 / 2$ test results from [1]. From this comparison, it can be seen that the model predicts rather well the scatter observed in the Series S1/2 results. These results can be assumed to contain some, but not all, batch effects as the specimens were fabricated using similar materials and 

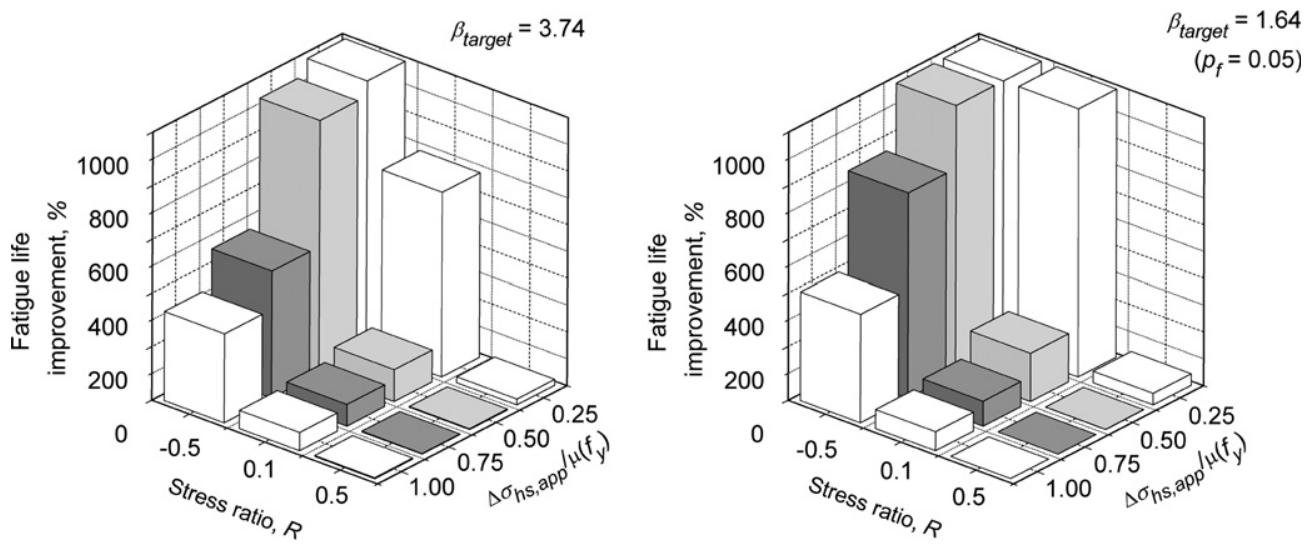

Fig. 15. Fatigue life improvement versus stress range and ratio.
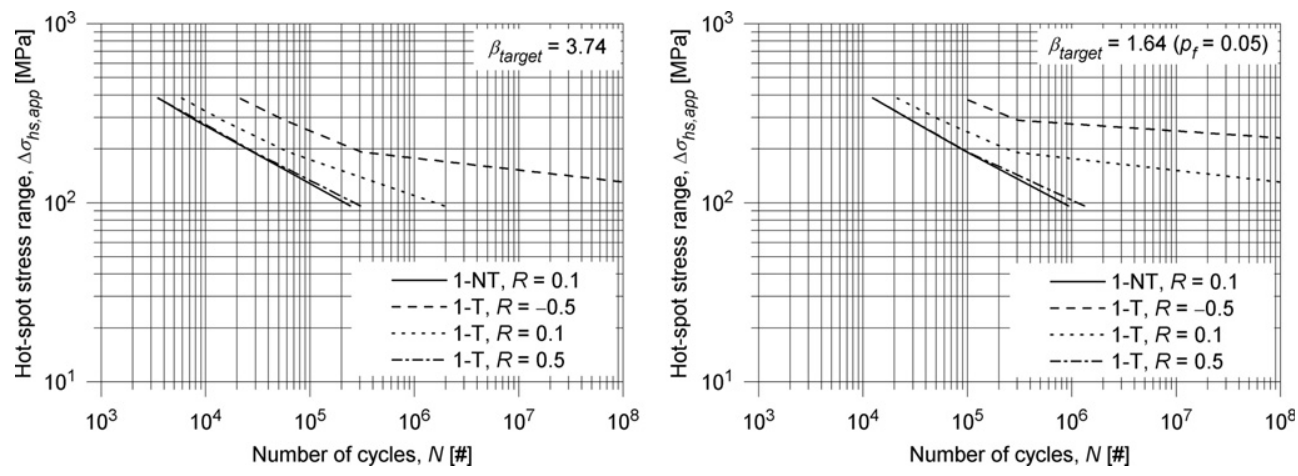

Fig. 16. $S-N$ curves based on applied stress range and ratio studies.

welding processes, but at different times and perhaps by different people. Notably, very different gaps, $g$, were observed between the brace walls in the Series S1 and S2 joints.

\section{Probabilistic model for tubular joints with multiple potential cracks sites}

The reliability of structural systems is discussed in a number of references, for example: [26]. Typically, simple structures and structural systems are distinguished, the the latter term being used to describe structures composed of multiple constituent elements. A number of researchers have employed a systems reliability approach in the fatigue analysis of welded structures with multiple potential crack sites, for example: [27-29]. Work in this area has typically been limited, however, to the development of models for determining optimum inspection strategies or (to a lesser extent) for establishing target reliability indices for design codes.

In general, complex systems can be idealized as simple series or parallel systems, or combinations of simple series and/or parallel sub-systems. In [3], tubular structures (i.e. joints or entire bridge trusses) with multiple potential crack sites are modelled as simple series systems, with each potential crack site considered as a single constituent element.

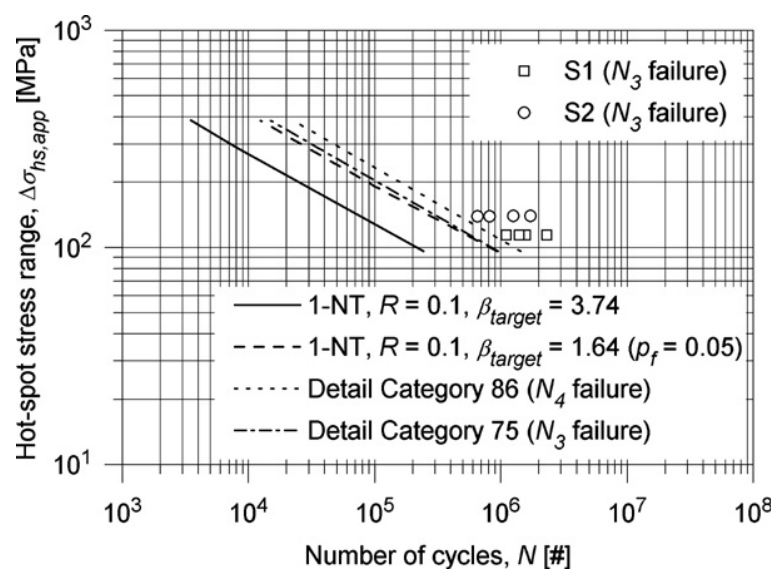

Fig. 17. Comparison of test data, calculated $S-N$ curves, and design curves (untreated joints).

Thus, failure of the structure is assumed to coincide with the failure of the first crack site. The justification given in [3] for this approach is as follows:

- It is believed that the simple series system model best reflects the fatigue behaviour of tubular joints. In general, tubular joints can and often do fail due to a crack occurring at one location and growing to a size sufficient 


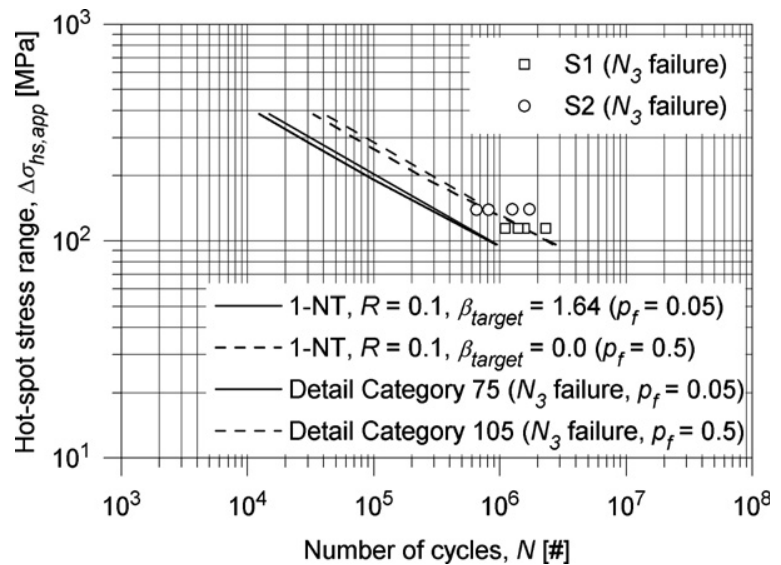

Fig. 18. Evaluation of predicted and observed scatter in the Series $\mathrm{S} 1 / 2$ test results.

to cause brittle fracture or plastic collapse. Crack coalescence (i.e. two cracks starting at adjacent defects and growing until they join to make one crack) has been observed [1], however it is believed that this phenomenon generally occurs at the level of the individual crack site, and thus, that it would be more appropriate to consider coalescence at this rather than the system level. Herein, this is done implicitly in the choice of the crack shape evolution function.

- Tubular joints are known to have a reserve life beyond the time required to cause through-thickness cracking at any single crack site [7]. Tubular bridge trusses may also have a reserve life beyond the time to failure of a single joint. Thus, the proposed model should give conservative estimates of the true levels of fatigue reliability of tubular joints and bridge trusses.

- An alternative to the proposed approach would be to consider tubular structures as parallel or complex systems that require the failure of multiple crack sites for structural collapse to occur. At the level of the joint, this would seem inappropriate, since total failure of the joint can occur due to a crack propagating from a single site. At the level of the entire bridge truss, failure modes involving multiple joints can be envisioned, however considering these would require a step-wise calculation, and thus, a computational effort much greater than that of the proposed approach.

- As was the case in the choice of the failure criterion for single crack sites, it can be argued that, despite its limitations, the adopted model can be used to make meaningful comparisons of the relative fatigue performances of tubular joints and bridge trusses with similar levels of redundancy.

In order to consider the tubular joint as a structural system, it must first be discretized into a suitable, finite number of constituent elements. Herein, it is assumed that the joint can be represented as a system comprised of 16 elements, corresponding with each of the potential crack sites identified in Fig. 19. In this figure, the designators ' $L$ ' and ' $R$ ' are adopted to indicate whether the site of interest is on the left or right brace. With the chosen discretization scheme, the probability of failure of each constituent element or crack site can be calculated using the probabilistic model developed in the previous section.

In reality, the weld toes of tubular joints can each be divided into an infinite number of potential crack sites, since the critical defect from which a crack eventually propagates can theoretically occur anywhere along their length. By assuming that the probability of failure of the joint can be determined knowing the probabilities of failure of each of the 16 representative potential crack sites in Fig. 19, certain simplifying assumptions are therefore implicitly being made. These can be summarized as follows:

- The true attributes of each of the infinite number of potential crack sites along the length of weld tributary to the representative potential crack site are fully (or highly) correlated, and

- The attributes assigned to each of the representative potential crack sites used to model the joint represent worst-case scenarios along the corresponding tributary weld lengths.

If these assumptions were entirely true, then there would be no error in the probability of failure calculated using the proposed model. Herein, it is assumed that these assumptions are more or less true, and thus, that the error associated with the proposed model is acceptably small.

The probability of failure of a series system consisting of $n$ elements can be expressed as follows:

$p_{\mathrm{f}}=P\left(E_{\text {system }}\right)=P\left(E_{1} \cup E_{2} \cup \ldots \cup E_{n}\right)$

wherein $E_{\text {system }}$ is the event of system failure, $E_{1}$ is the event of failure of element 1 , etc. If the probabilities of failure of the individual system elements are assumed to be fully independent, then the probability of system failure can be calculated as follows [26]:

$p_{\mathrm{f}, \text { system }}=1-\left(1-p_{\mathrm{f}, 1}\right) \cdot\left(1-p_{\mathrm{f}, 2}\right) \cdots\left(1-p_{\mathrm{f}, n}\right)$

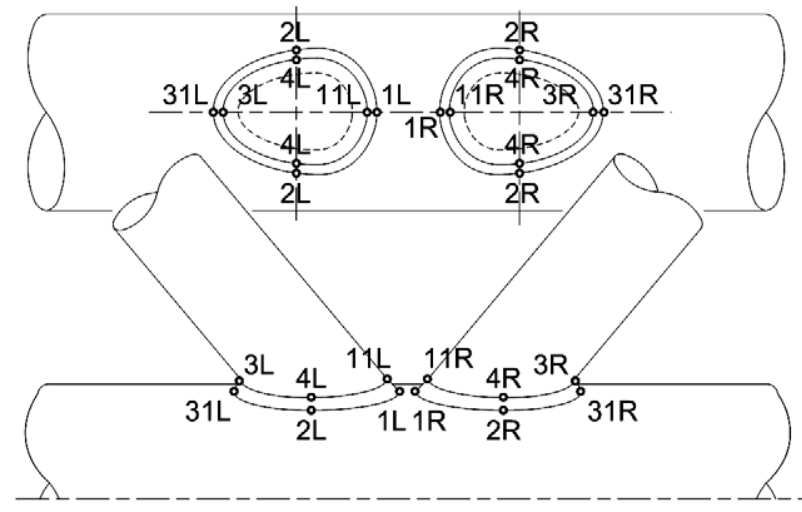

Fig. 19. Discretization of the joint. 
wherein $p_{\mathrm{f}, \text { system }}$ is the probability of system failure, $p_{\mathrm{f}, 1}$ is the probability of failure of element 1 , etc. To describe the probability of failure of a tubular $K$-joint, this formula can be rewritten as follows:

$p_{\mathrm{f}, \text { joint }}=1-\left(1-p_{\mathrm{f}, 1 L}\right) \cdot\left(1-p_{\mathrm{f}, 11 L}\right) \cdots\left(1-p_{f, 4 R}\right)$

wherein $p_{\mathrm{f}, \text { joint }}$ is the probability of joint failure, $p_{\mathrm{f}, 1 L}$ is the probability of failure of Site 1L, etc. In Eq. (21), there are, in fact, 16 terms corresponding with each of the crack sites in Fig. 19. Only 12 single site analyses are required, however, since the results for Sites $2 \mathrm{~L}, 4 \mathrm{~L}, 2 \mathrm{R}$, and $4 \mathrm{R}$ can each be used twice. Eq. (20) is often referred to as the first order lower bound reliability $(\beta)$ model for series systems (note: in fact it gives an upper bound estimate of the probability of failure, $p_{\mathrm{f}}$ ).

In order to consider the effects of possible correlations between the reliabilities of the individual system elements, an upper bound reliability model for series systems is employed. This model assumes full correlation of the reliabilities or probabilities of failure of each potential crack site. Although this scenario seems unlikely in reality, it is of interest to compare the results obtained using the lower and upper bound models to determine the significance (if any) of the true correlation level. The probability of failure of the joint according to the upper bound reliability model can be calculated as follows [26]:

$p_{\mathrm{f}, \text { joint }}=\operatorname{MAX}\left(p_{\mathrm{f}, 1 L}, p_{\mathrm{f}, 11 L}, \ldots, p_{\mathrm{f}, 4 R}\right)$

Using Eqs. (21) and (22), envelopes of the reliability of the entire joint versus the number of applied load cycles can be generated. In [3], this approach is extended for the analysis of entire tubular bridge trusses with multiple joints. In or-

Table 4

Load cases for $K$-joints from [1]

\begin{tabular}{lll}
\hline Load case & Nominal stress \\
Balanced axial brace & Schematic & $\sigma_{\text {ax_br }}$ \\
Bnbalanced in-plane bending brace & $\sigma_{\text {ipb1_br }}$ \\
Anial chord & $\sigma_{\text {ipb2_br }}$ \\
\hline
\end{tabular}

der to first demonstrate this approach for single joints, however, a number of calculations were carried out on the Series S1/2/4 joint geometry studied in [1]. Since FE analysis results were only available for Site 1 , the $\Delta \sigma_{\mathrm{hs} \text {,app }}$ and $D O B$ parameters for each of the 16 potential crack sites had to be determined by other means. Nominal member strain data was available for the tested joints, as reported in [1]. Using this data, along with the $S C F$ tables from the same reference for tubular joints with dimensions common to bridge structures $(4.2 \leqslant \gamma \leqslant 12.7), \Delta \sigma_{\mathrm{hs}, \text { app }}$ was determined for each hot-spot using the following expression, wherein the hot-spot stress is determined given the nominal member stress ranges corresponding with the five simple load cases in Table 4:

$$
\begin{aligned}
& \Delta \sigma_{\mathrm{hs}, \mathrm{app}}=\Delta \sigma_{\mathrm{ax} \_ \text {br }} \cdot S C F_{\mathrm{ax} \_ \text {br }}+\Delta \sigma_{\mathrm{ax} \_c h} \cdot S C F_{\mathrm{ax} \_c h} \\
& +\Delta \sigma_{\mathrm{ipb1} \_b r} \cdot S C F_{\mathrm{ipb} 1 \_b r}+\Delta \sigma_{\mathrm{ipb} 2 \_b r} \\
& \cdot S C F_{\text {ipb2_br }}+\Delta \sigma_{\text {ipb_ch }} \cdot S C F_{\text {ipb_ch }}
\end{aligned}
$$

In this expression, $\Delta \sigma_{\text {ax } \_ \text {br }}$ is the nominal member stress range due to the balanced axial brace load case and $S C F_{\text {ax br }}$ is the corresponding stress concentration factor, etc. The $S C F$ tables in [1] require as input the following parameters: $\beta(=0.5 \cdot d / D), \gamma, \tau(=t / T)$, and $\theta_{\mathrm{br}}$.

For lack of a viable alternative, the parametric equations from [15] were used to determine the values for the $D O B$ at each hot-spot, with some assumptions for the missing load cases and ignoring the lower limit on $\gamma$. The implications of this choice were deemed acceptable, as discussed in [3]. The parametric equations in [15] require as input the following parameters: $\alpha\left(=2 \cdot L_{\mathrm{ch}} / D\right), \beta, \gamma, \tau$, and $\theta_{\mathrm{br}}$. For each crack site, the critical crack depth was taken as half of the wall thickness of the cracked member. The weld geometry parameters, $L_{\mathrm{w}}$ and $\theta_{\mathrm{w}}$, were measured on a specimen sectioned after testing.

Table 5 summarizes the values of the site-specific parameters used in this analysis (see Table 1 for the additional joint geometry parameters). Based on this information, $\beta$ versus $N$ curves for each of the potential crack sites in the untreated joint and the joint with Site 1L (Site 1 on the tension brace) treated are presented in Fig. 20. In this figure, it can be seen that the second most critical crack site (after Site 1L) is Site 11L. The fact that this site is seen to be weaker than Site 1R (where cracks were observed in the Series 4 tests) is believed to be due partly to the use of a common critical crack depth for all sites and partly to

\begin{tabular}{|c|c|c|c|c|c|c|c|c|c|c|c|c|}
\hline \multirow[t]{2}{*}{ Parameter $^{\mathrm{a}}$} & \multicolumn{6}{|c|}{ Tension brace } & \multicolumn{6}{|c|}{ Compression brace } \\
\hline & $1 \mathrm{~L}$ & $11 \mathrm{~L}$ & $2 \mathrm{~L}$ & $3 \mathrm{~L}$ & $31 \mathrm{~L}$ & $4 \mathrm{~L}$ & $1 \mathrm{R}$ & $11 \mathrm{R}$ & $2 \mathrm{R}$ & $3 R$ & $31 \mathrm{R}$ & $4 \mathrm{R}$ \\
\hline$\Delta \sigma_{\mathrm{hs}, \mathrm{app}}$ & 160.5 & 106.7 & 84.8 & 11.9 & 40.5 & 81.5 & -92.4 & -96.9 & -88.4 & -57.9 & -24.1 & -83.0 \\
\hline$D O B$ & 0.77 & 0.83 & 0.77 & 0.74 & 0.77 & 0.74 & 0.77 & 0.83 & 0.77 & 0.74 & 0.77 & 0.74 \\
\hline$L_{\mathrm{w}}$ & 21 & 37 & 32 & 41 & 32 & 44 & 21 & 37 & 32 & 41 & 32 & 44 \\
\hline
\end{tabular}

Table 5

Site-specific input parameters for the Series $\mathrm{S} 1 / 2 / 4$ specimen size

${ }^{\mathrm{a}}$ Note: $\triangle \sigma_{\mathrm{hs}, \text { app }}$ in $\mathrm{MPa}, D O B$ unitless, $\theta_{\mathrm{w}}$ in ${ }^{\circ}, L_{\mathrm{w}}$ in $\mathrm{mm}$. 

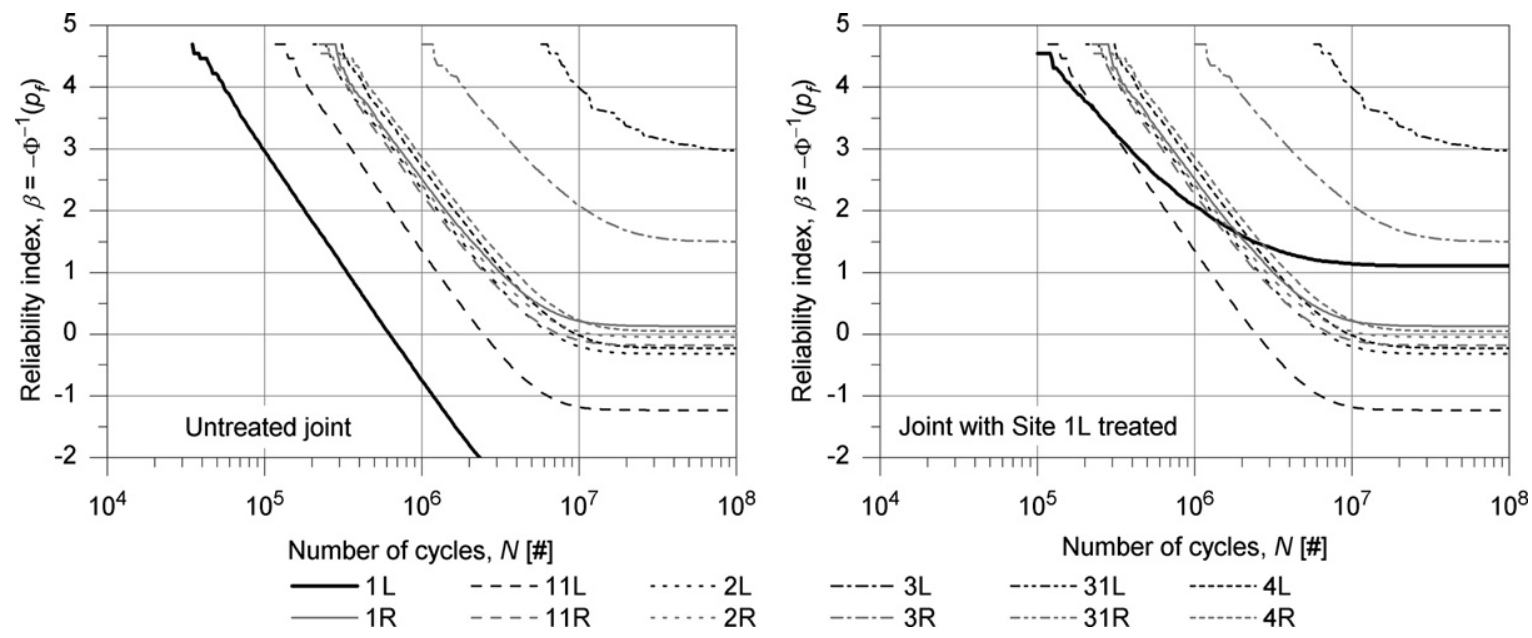

Fig. 20. $\beta$ versus $N$ curves for single sites in untreated and treated joints.

the observed systematic differences in the brace and chordside weld toes caused by the position of the joint during welding, as discussed in [3]. Since the model was calibrated using data for cracks on the systematically weaker chordside weld toe, these differences could be safely ignored.

In Fig. 21, envelopes of the reliability of the joint, determined using the lower and upper bound reliability models, are presented. In this figure, it can be seen that a significant improvement in the overall reliability of the joint is achieved with post-weld treatment, even when the influences of the various untreated potential crack sites are considered. It can also be seen that although the two models give diverging results at the lower reliability indices, at the higher indices the difference between the two models is small. In general, this latter trend will be apparent whenever the overall reliability of the joint is determined by a small number of relatively weak potential crack sites, as is the case here. In Fig. 21, two treatment strategies are compared: treating the critical crack site (Site 1L) only and treating the entire joint. Looking at this figure it can be seen that when comparisons are made at high target reli-

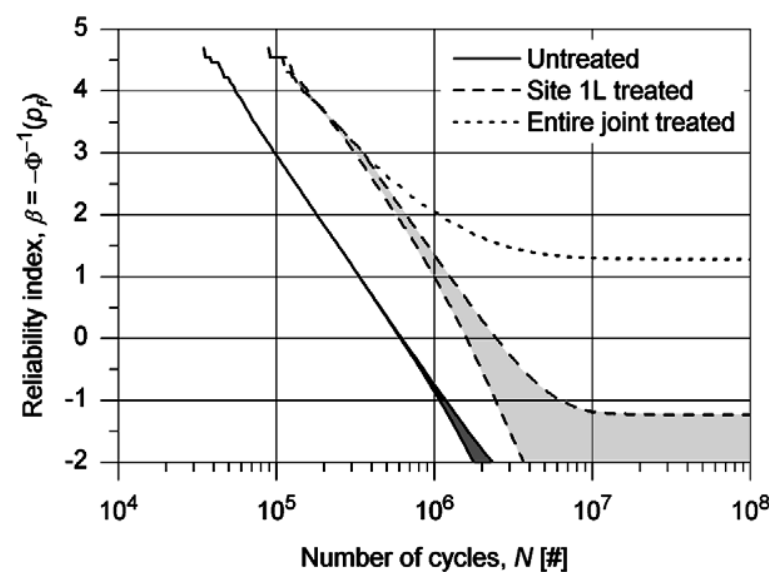

Fig. 21. Reliability envelopes for untreated and treated joints. ability indices, there is almost no benefit in treating sites other than the critical one for this joint.

\section{Conclusions}

Based on the work presented herein, the following conclusions are drawn:

- The deterministic and probabilistic single site models developed herein are able to predict the shift in the critical crack site observed in the fatigue tests reported in $[1,2]$.

- Using the probabilistic single site model developed herein, it is demonstrated that significant increases in the fatigue lives of single potential crack sites in tubular bridge joints can be reliably achieved by needle peening, under certain constant amplitude loading conditions. In general, the higher the applied stress range or ratio, the lower the benefit of post-weld treatment. For higher stress ranges and ratios, there may in fact be no treatment benefit.

- Increasing the treatment intensity will result in a significant increase in the effectiveness of residual stress-based treatment methods such as needle peening. Likewise, increasing the treatment uniformity or quality will also result in an increase in the effectiveness of these methods. In general, however, the treatment benefit is more sensitive to treatment intensity than quality.

- The fatigue reliability of tubular structures with multiple potential crack sites can be predicted using first order lower and upper bound reliability models for series systems. The reliabilities of tubular joints are often determined by one or two crack sites. Thus, the two models tend to give converging results for the higher $\beta_{\text {target }}$ indices often used in the design of civil engineering structures.

- The current work demonstrates that significant improvements in the fatigue performance of tubular bridge joints can be obtained with post-weld treatment, even when 
the influences of the various untreated and treated potential crack sites on the overall reliability of the joint are considered.

Although its immediate scope is limited to the post-weld treatment of tubular joints with geometries common to bridge structures, it is believed that the possible applications of the work presented herein are wide-ranging. Specifically, it is believed that the models developed herein can be used, essentially in their current form, for the analysis of tubular joints in offshore structures. A similar approach could also be used for analyzing the effects of treating plate structures such as plate girder bridges.

A number of issues are not addressed in this article, which may have a significant influence on the potential of post-weld treatment methods for improving the fatigue performance of tubular bridge joints. Some of these issues are examined in [3]. These include the effect on the predicted treatment benefit of considering realistic, variable amplitude loading conditions, the influence of fatigue cracking at untreatable locations such as the weld root, and the effect of post-weld treatment on the fatigue performance of entire bridge trusses with multiple joints. The models presented herein provide important results, however, and a foundation for the study of these other issues.

\section{Acknowledgements}

The work presented herein was supported financially by the Swiss Federal Roads Authority (OFROU Project No. AGB2002/011) and the Swiss National Research Foundation (SNF Grant 200020-101521).

\section{References}

[1] Schumacher A. Fatigue behaviour of welded circular hollow section joints in bridges. EPFL thesis no. 2727, Lausanne; 2003. Available from: http://icom.epfl.ch.

[2] Schumacher A, Nussbaumer A. Experimental study on the fatigue behaviour of welded tubular $K$-joints for bridges. Eng Struct 2006;28(5):745-55.

[3] Walbridge S. A probabilistic study of fatigue in post-weld treated tubular bridge structures. EPFL thesis no. 3330, Lausanne; 2005. Available from: http://icom.epfl.ch.

[4] Kirkhope KJ, Bell R, Caron L, Basu RI, Ma K-T. Weld detail fatigue life improvement techniques - Part 1: review. Mar Struct 1999;12: 447-74.

[5] Haagensen PJ, Maddox SJ. IIW Recommendations on the post weld improvement of steel and aluminium structures. Doc. XIII-1815-00, International Institute of Welding; 2000.

[6] Bremen, U. Amelioration du comportement à la fatigue d'assemblages soudés: étude et modelisation de l'effet de contraintes residuelles. EPFL thesis no. 787, Lausanne; 1989.

[7] van Wingerde AM, van Delft DRV, Wardenier J, Packer JA. Scale effects on the fatigue behaviour of tubular structures. In: WRC proceedings. International Institute of Welding; 1997. p. 123-35.
[8] Albrecht P, Yamada K. Rapid calculation of stress intensity factors. J Struct Eng 1977;103(ST2):377-89.

[9] Irwin GR. Crack-extension force for a part-through crack in a plate. J Appl Mech 1962;E(29):651-4.

[10] Hirt MA, Bez R. Traité de Génie Civil de l'EPFL Volume 10 Construction Métallique. Presses Polytechniques et Universitaires Romandes, Lausanne; 1996.

[11] Irwin GR, Liebowitz H, Paris PC. A mystery of fracture mechanics. Eng Fract Mech 1968;3:235-6.

[12] Stacey A, Barthelemy J-Y, Leggatt RH, Ainsworth RA. Incorporation of residual stresses into the SINTAP defect assessment procedure. Eng Fract Mech 2000;67:573-611.

[13] Bowness D, Lee MMK. Weld toe magnification factors for semi-elliptical cracks in $T$-butt joints. Offshore technology report - OTO 199 014, Health and Safety Executive (HSE), UK; 1999.

[14] Newman JC, Raju IS. An empirical stress-intensity factor equation for the surface crack. Eng Fract Mech 1981;15(1-2):185-92.

[15] Connolly MP, Hellier AK, Dover WD, Sutomo J. A parametric study of the ratio of bending to membrane stress in tubular Y- and T-joints. Int J Fatigue 1990;1:3-11.

[16] Shetty NK, Baker MJ. Fatigue reliability of tubular joints in offshore structures: fatigue loading. In: Proceedings of the 9th international conference on offshore mechanics and artic engineering, vol. II; 1990. p. $33-40$.

[17] Shetty NK, Baker MJ. Fatigue reliability of tubular joints in offshore structures: crack propagation model. In: Proceedings of the 9th international conference on offshore mechanics and artic engineering, vol. II; 1990. p. 223-30.

[18] Shetty NK, Baker MJ. Fatigue reliability of tubular joints in offshore structures: reliability analysis. In: Proceedings of the 9th international conference on offshore mechanics and artic engineering, vol. II; 1990. p. 231-9.

[19] Lukic M, Cremona C. Probabilistic assessment of welded joints versus fatigue and fracture. J Struct Eng 2001;127:211-8.

[20] Lukic M. Evaluation de maintenance probabilistes des assemblages soudés vis-à-vis de la fatigue et de la rupture - application aux ponts mixtes. Thesis report, Ecole Nationale des Ponts et Chaussés, France; 1999.

[21] Porter Goff RFD, Free JA, Tsiagbe WZ. Residual stresses in welded tubular nodes. Fatigue Offshore Struct 1988:285-95.

[22] Joint Committee on Structural Safety (JCSS). Probabilistic mode code; 2001. Internet publication: Available from: http://www.jcss. ethz.ch.

[23] International Institute of Welding (IIW). Document: XIII-1965-03/ $\mathrm{XV}-1127-03$ - Recommendations for fatigue design of welded joints and components. Germany; 2005.

[24] Swiss Society of Engineers and Architects (SIA). SIA 260/261/ 263:2003 - basis for structural design/actions on structures/steel structures. Zurich; 2003.

[25] European Committee for Standardization. EN1990 - basis of structural design. Brussels; 2002.

[26] Melchers RE. Structural reliability analysis and prediction. 2nd ed. John Wiley and Sons; 1999.

[27] Lotsberg I, Sigurdsson G, Wold PT. Probabilistic inspection planning of the asgard A FPSO hull structure with respect to fatigue. J Offshore Mech Arctic Eng 2000;122: 134-40.

[28] Moan T, Song R. Implications of inspection and repair on system fatigue reliability of offshore structures. J Offshore Mech Arctic Eng 2000;122:173-80.

[29] Straub D, Faber MH. System effects in generic risk based inspection planning. In: Proceedings of the 21 st offshore mechanics and arctic engineering conference. ASME; 2002. 